\title{
Isolation and characterization of a bat SARS-like coronavirus that uses the ACE2 receptor
}

\author{
Xing-Yi Ge ${ }^{1 *}$, Jia-Lu Li ${ }^{1 *}$, Xing-Lou Yang ${ }^{1 *}$, Aleksei A. Chmura ${ }^{2}$, Guangjian Zhu ${ }^{2}$, Jonathan H. Epstein ${ }^{2}$, Jonna K. Mazet ${ }^{3}$, Ben Hu ${ }^{1}$, \\ Wei Zhang ${ }^{1}$, Cheng Peng ${ }^{1}$, Yu-Ji Zhang ${ }^{1}$, Chu-Ming Luo ${ }^{1}$, Bing Tan ${ }^{1}$, Ning Wang ${ }^{1}$, Yan Zhu ${ }^{1}$, Gary Crameri ${ }^{4}$, Shu-Yi Zhang ${ }^{5}$, \\ Lin-Fa Wang ${ }^{4,6}$, Peter Daszak ${ }^{2}$ \& Zheng-Li Shi ${ }^{1}$
}

The 2002-3 pandemic caused by severe acute respiratory syndrome coronavirus (SARS-CoV) was one of the most significant public health events in recent history ${ }^{1}$. An ongoing outbreak of Middle East respiratory syndrome coronavirus ${ }^{2}$ suggests that this group of viruses remains a key threat and that their distribution is wider than previously recognized. Although bats have been suggested to be the natural reservoirs of both viruses $^{3-5}$, attempts to isolate the progenitor virus of SARSCoV from bats have been unsuccessful. Diverse SARS-like coronaviruses (SL-CoVs) have now been reported from bats in China, Europe and Africa ${ }^{5-8}$, but none is considered a direct progenitor of SARS-CoV because of their phylogenetic disparity from this virus and the inability of their spike proteins to use the SARS-CoV cellular receptor molecule, the human angiotensin converting enzyme II (ACE2) ${ }^{9,10}$. Here we report whole-genome sequences of two novel bat coronaviruses from Chinese horseshoe bats (family: Rhinolophidae) in Yunnan, China: RsSHC014 and Rs3367. These viruses are far more closely related to SARS-CoV than any previously identified bat coronaviruses, particularly in the receptor binding domain of the spike protein. Most importantly, we report the first recorded isolation of a live SL-CoV (bat SL-CoV-WIV1) from bat faecal samples in Vero E6 cells, which has typical coronavirus morphology, $99.9 \%$ sequence identity to Rs3367 and uses ACE2 from humans, civets and Chinese horseshoe bats for cell entry. Preliminary in vitro testing indicates that WIV1 also has a broad species tropism. Our results provide the strongest evidence to date that Chinese horseshoe bats are natural reservoirs of SARS-CoV, and that intermediate hosts may not be necessary for direct human infection by some bat SL-CoVs. They also highlight the importance of pathogen-discovery programs targeting high-risk wildlife groups in emerging disease hotspots as a strategy for pandemic preparedness.

The 2002-3 pandemic of SARS ${ }^{1}$ and the ongoing emergence of the Middle East respiratory syndrome coronavirus (MERS-CoV) ${ }^{2}$ demonstrate that $\mathrm{CoVs}$ are a significant public health threat. SARS-CoV was shown to use the human ACE2 molecule as its entry receptor, and this is considered a hallmark of its cross-species transmissibility ${ }^{11}$. The receptor binding domain (RBD) located in the amino-terminal region (amino acids 318-510) of the SARS-CoV spike (S) protein is directly involved in binding to ACE2 (ref. 12). However, despite phylogenetic evidence that SARS-CoV evolved from bat SL-CoVs, all previously identified SL-CoVs have major sequence differences from SARS-CoV in the RBD of their S proteins, including one or two deletions ${ }^{6,9}$. Replacing the RBD of one SL-CoV S protein with SARS-CoV S conferred the ability to use human ACE2 and replicate efficiently in mice ${ }^{9,13}$. However, to date, no SL-CoVs have been isolated from bats, and no wild-type SL-CoV of bat origin has been shown to use ACE2.

We conducted a 12-month longitudinal survey (April 2011-September 2012) of SL-CoVs in a colony of Rhinolophus sinicus at a single location in Kunming, Yunnan Province, China (Extended Data Table 1). A total of 117 anal swabs or faecal samples were collected from individual bats using a previously published method ${ }^{5,14}$. A one-step reverse transcription (RT)-nested PCR was conducted to amplify the RNA-dependent RNA polymerase (RdRP) motifs A and C, which are conserved among alphacoronaviruses and betacoronaviruses ${ }^{15}$.

Twenty-seven of the 117 samples (23\%) were classed as positive by PCR and subsequently confirmed by sequencing. The species origin of all positive samples was confirmed to be $R$. sinicus by cytochrome b sequence analysis, as described previously ${ }^{16}$. A higher prevalence was observed in samples collected in October (30\% in 2011 and $48.7 \%$ in 2012) than those in April (7.1\% in 2011) or May (7.4\% in 2012) (Extended Data Table 1). Analysis of the $S$ protein RBD sequences indicated the presence of seven different strains of SL-CoVs (Fig. 1a and Extended Data Figs 1 and 2). In addition to RBD sequences, which closely matched previously described SL-CoVs (Rs672, Rf1 and HKU3) (5, $, 17,18^{\text {, two novel }}$ strains (designated SL-CoV RsSHC014 and Rs3367) were discovered. Their full-length genome sequences were determined, and both were found to be 29,787 base pairs in size (excluding the poly(A) tail). The overall nucleotide sequence identity of these two genomes with human SARS-CoV (Tor2 strain) is 95\%, higher than that observed previously for bat SL-CoVs in China (88-92\%) $)^{5,8,17,18}$ or Europe $(76 \%)^{6}$ (Extended Data Table 2 and Extended Data Figs 3 and 4). Higher sequence identities were observed at the protein level between these new SL-CoVs and SARS-CoVs (Extended Data Tables 3 and 4). To understand the evolutionary origin of these two novel SL-CoV strains, we conducted recombination analysis with the Recombination Detection Program 4.0 package $^{19}$ using available genome sequences of bat SL-CoV strains (Rf1, Rp3, Rs672, Rm1, HKU3 and BM48-31) and human and civet representative SARS-CoV strains (BJ01, SZ3, Tor2 and GZ02). Three breakpoints were detected with strong $P$ values $\left(<10^{-20}\right)$ and supported by similarity plot and bootscan analysis (Extended Data Fig. 5a, b). Breakpoints were located at nucleotides $20,827,26,553$ and 28,685 in the Rs3367 (and RsSHC014) genome, and generated recombination fragments covering nucleotides 20,827-26,533 (5,727 nucleotides) (including partial open reading frame (ORF) $1 \mathrm{~b}$, full-length $\mathrm{S}, \mathrm{ORF} 3, \mathrm{E}$ and partial $M$ gene) and nucleotides 26,534-28,685 (2,133 nucleotides) (including partial ORF M, full-length ORF6, ORF7, ORF8 and partial N gene). Phylogenetic analysis using the major and minor parental regions suggested that Rs3367, or RsSHC014, is the descendent of a recombination of lineages that ultimately lead to SARS-CoV and SL-CoV Rs672 (Fig. 1b).

The most notable sequence differences between these two new SLCoVs and previously identified SL-CoVs is in the RBD regions of their S proteins. First, they have higher amino acid sequence identity to SARSCoV (85\% and 96\% for RsSHC014 and Rs3367, respectively). Second, there are no deletions and they have perfect sequence alignment with the SARS-CoV RBD region (Extended Data Figs 1 and 2). Structural

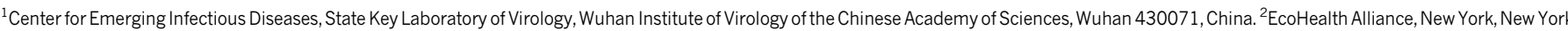

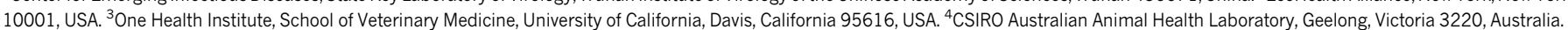
${ }^{5}$ College of Life Sciences, East China Normal University, Shanghai 200062, China. ${ }^{6}$ Emerging Infectious Diseases Program, Duke-NUS Graduate Medical School, Singapore 169857.

*These authors contributed equally to this work. 


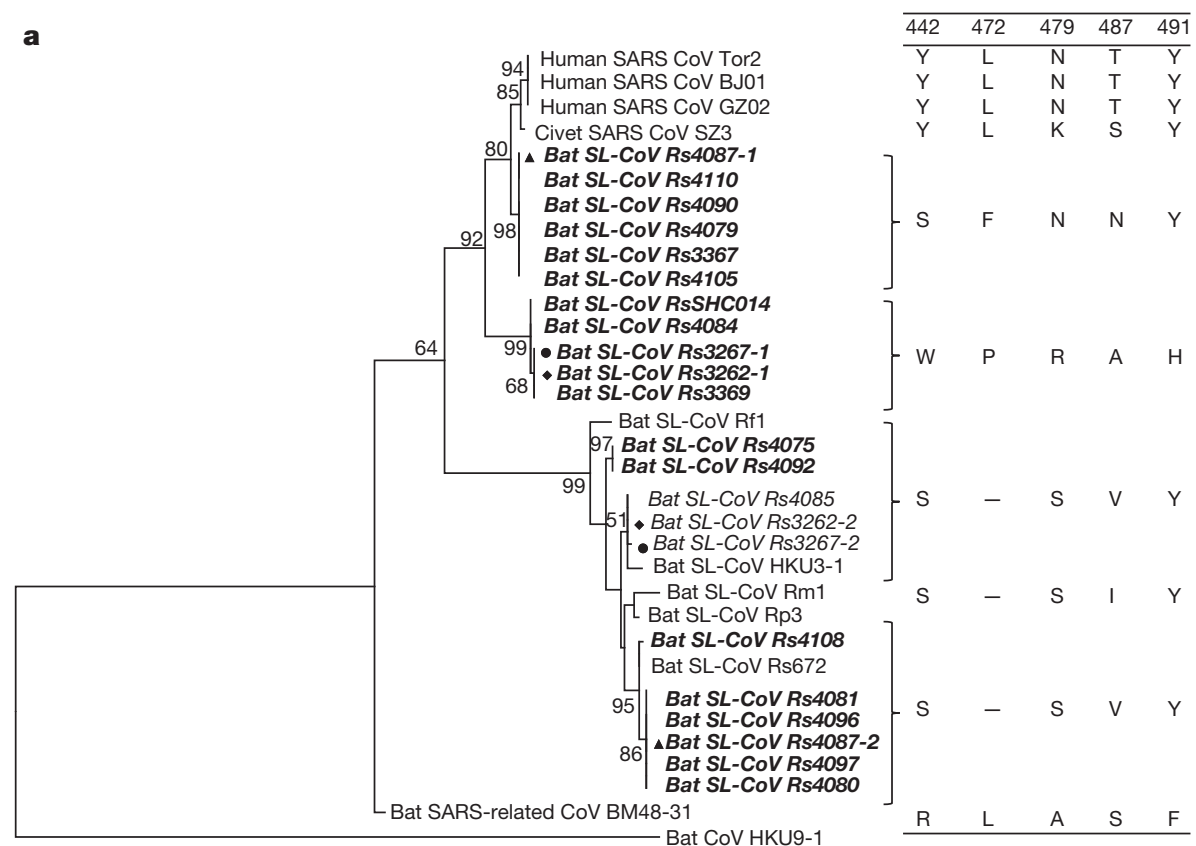

0.2
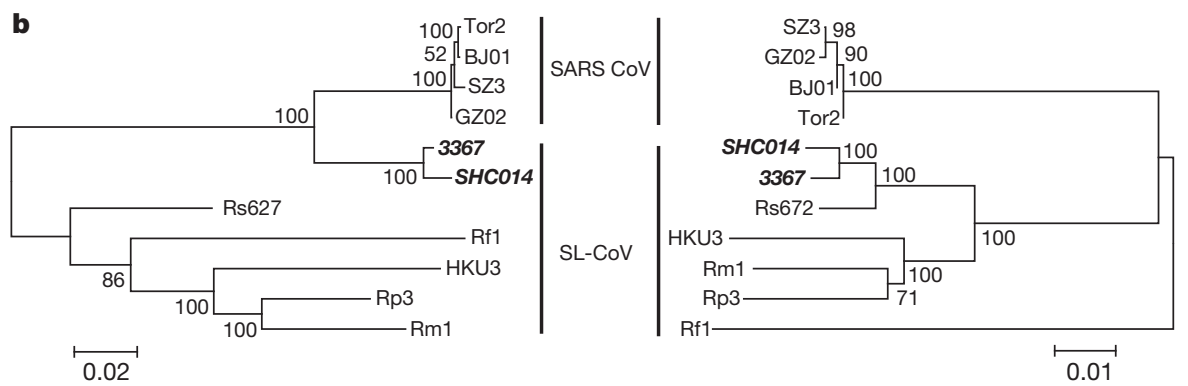

Figure 1 Phylogenetic tree based on amino acid sequences of the S RBD region and the two parental regions of bat SL-CoV Rs3367 or RsSHC014. a, SARS-CoV S protein amino acid residues $310-520$ were aligned with homologous regions of bat SL-CoVs using the ClustalW software. A maximumlikelihood phylogenetic tree was constructed using a Poisson model with bootstrap values determined by 1,000 replicates in the MEGA5 software package. The RBD sequences identified in this study are in bold and named by the sample numbers. The key amino acid residues involved in interacting with the human ACE2 molecule are indicated on the right of the tree. SARS-CoV GZ02, BJ01 and Tor2 were isolated from patients in the early, middle and late phase, respectively, of the SARS outbreak in 2003. SARS-CoV SZ3 was identified from Paguma larvata in 2003 collected in Guangdong, China. SL-CoV Rp3, Rs672 and HKU3-1 were identified from R. sinicus collected in China (respectively: Guangxi, 2004; Guizhou, 2006; Hong Kong, 2005). Rf1 and Rm1 were identified from

and mutagenesis studies have previously identified five key residues (amino acids 442, 472, 479, 487 and 491) in the RBD of the SARS-CoV $S$ protein that have a pivotal role in receptor binding ${ }^{20,21}$. Although all five residues in the RsSHC014 S protein were found to be different from those of SARS-CoV, two of the five residues in the Rs3367 RBD were conserved (Fig. 1 and Extended Data Fig. 1).

Despite the rapid accumulation of bat $\mathrm{CoV}$ sequences in the last decade, there has been no report of successful virus isolation ${ }^{6,22,23}$. We attempted isolation from SL-CoV PCR-positive samples. Using an optimized protocol and Vero E6 cells, we obtained one isolate which caused cytopathic effect during the second blind passage. Purified virions displayed typical coronavirus morphology under electron microscopy (Fig. 2). Sequence analysis using a sequence-independent amplification method ${ }^{14}$ to avoid PCR-introduced contamination indicated that the isolate was almost identical to Rs 3367 , with $99.9 \%$ nucleotide genome sequence identity and $100 \%$ amino acid sequence identity for the S1 region. The new isolate was named SL-CoV-WIV1.
R. ferrumequinum and R. macrotis, respectively, collected in Hubei, China, in 2004. Bat SARS-related CoV BM48-31 was identified from $R$. blasii collected in Bulgaria in 2008. Bat CoV HKU9-1 was identified from Rousettus leschenaultii collected in Guangdong, China in 2005/2006 and used as an outgroup. All sequences in bold and italics were identified in the current study. Filled triangles, circles and diamonds indicate samples with co-infection by two different SL-CoVs. '-' indicates the amino acid deletion. b, Phylogenetic origins of the two parental regions of Rs3367 or RsSHC014. Maximum likelihood phylogenetic trees were constructed from alignments of two fragments covering nucleotides 20,827-26,533 (5,727 nucleotides) and 26,534 -28,685 (2,133 nucleotides) of the Rs3367 genome, respectively. For display purposes, the trees were midpoint rooted. The taxa were annotated according to strain names: SARS-CoV, SARS coronavirus; SARS-like CoV, bat SARS-like coronavirus. The two novel SL-CoVs, Rs3367 and RsSHC014, are in bold and italics.

To determine whether WIV1 can use ACE2 as a cellular entry receptor, we conducted virus infectivity studies using HeLa cells expressing or not expressing ACE2 from humans, civets or Chinese horseshoe bats. We found that WIV1 is able to use ACE2 of different origins as an entry receptor and replicated efficiently in the ACE2-expressing cells (Fig. 3). This is, to our knowledge, the first identification of a wild-type bat SL$\mathrm{CoV}$ capable of using ACE2 as an entry receptor.

To assess its cross-species transmission potential, we conducted infectivity assays in cell lines from a range of species. Our results (Fig. 4 and Extended Data Table 5) indicate that bat SL-CoV-WIV1 can grow in human alveolar basal epithelial (A549), pig kidney 15 (PK-15) and Rhinolophus sinicus kidney (RSKT) cell lines, but not in human cervix (HeLa), Syrian golden hamster kidney (BHK21), Myotis davidii kidney (BK), Myotis chinensis kidney (MCKT), Rousettus leschenaulti kidney (RLK) or Pteropus alecto kidney (PaKi) cell lines. Real-time RT-PCR indicated that WIV1 replicated much less efficiently in A549, PK-15 and RSKT cells than in Vero E6 cells (Fig. 4). 


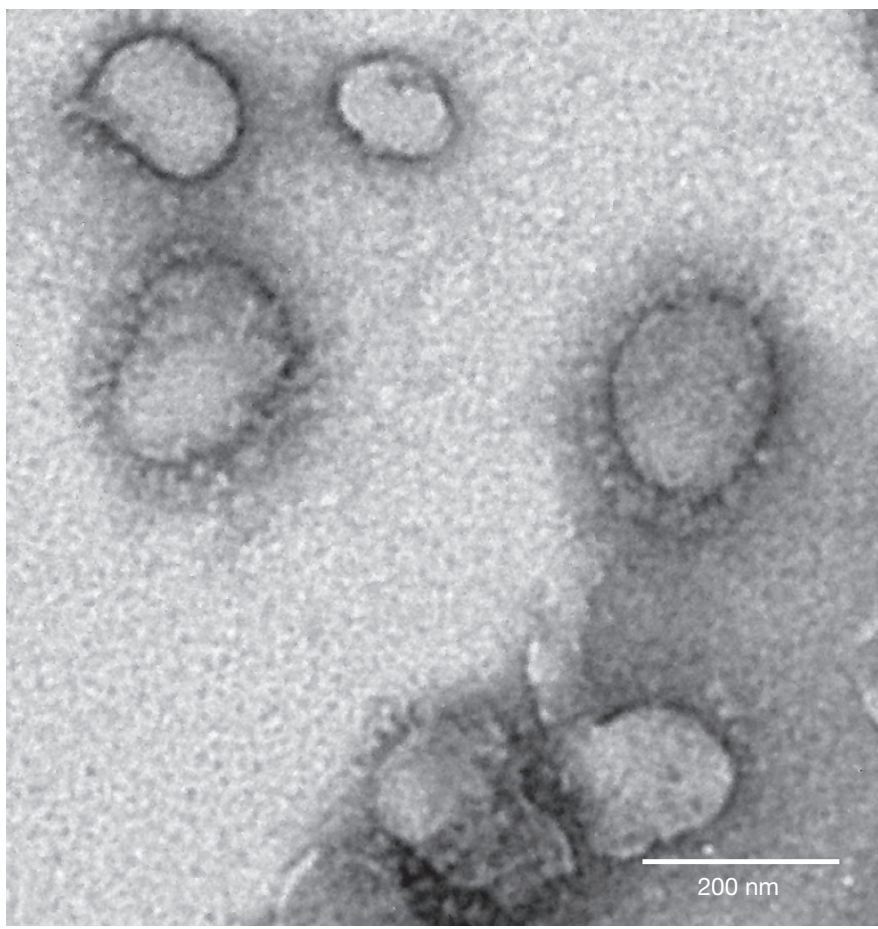

Figure $2 \mid$ Electron micrograph of purified virions. Virions from a $10-\mathrm{ml}$ culture were collected, fixed and concentrated/purified by sucrose gradient centrifugation. The pelleted viral particles were suspended in $100 \mu \mathrm{lBS}$, stained with $2 \%$ phosphotungstic acid ( $\mathrm{pH} 7.0)$ and examined directly using a Tecnai transmission electron microscope (FEI) at $200 \mathrm{kV}$.

To assess the cross-neutralization activity of human SARS-CoV sera against WIV1, we conducted serum-neutralization assays using nine convalescent sera from SARS patients collected in 2003. The results showed that seven of these were able to completely neutralize 100 tissue culture infectious dose $50\left(\mathrm{TCID}_{50}\right)$ WIV1 at dilutions of 1:10 to 1:40, further confirming the close relationship between WIV1 and SARS-CoV.

Our findings have important implications for public health. First, they provide the clearest evidence yet that SARS-CoV originated in bats. Our previous work provided phylogenetic evidence of this ${ }^{5}$, but the lack of an isolate or evidence that bat SL-CoVs can naturally infect human cells, until now, had cast doubt on this hypothesis. Second, the lack of capacity of SL-CoVs to use of ACE2 receptors has previously been considered as the key barrier for their direct spillover into humans, supporting the suggestion that civets were intermediate hosts for SARS-CoV adaptation to human transmission during the SARS outbreak ${ }^{24}$. However, the ability of SL-CoV-WIV1 to use human ACE2 argues against the necessity of this step for SL-CoV-WIV1 and suggests that direct batto-human infection is a plausible scenario for some bat SL-CoVs. This has implications for public health control measures in the face of potential spillover of a diverse and growing pool of recently discovered SARSlike $\mathrm{CoVs}$ with a wide geographic distribution.

Our findings suggest that the diversity of bat CoVs is substantially higher than that previously reported. In this study we were able to demonstrate the circulation of at least seven different strains of SL-CoVs within a single colony of $R$. sinicus during a 12-month period. The high genetic diversity of SL-CoVs within this colony was mirrored by high phenotypic diversity in the differential use of ACE2 by different strains. It would therefore not be surprising if further surveillance reveals a broad diversity of bat SL-CoVs that are able to use ACE2, some of which may have even closer homology to SARS-CoV than SL-CoV-WIV1. Our results-in addition to the recent demonstration of MERS-CoV in a Saudi Arabian bat ${ }^{25}$, and of bat CoVs closely related to MERS-CoV in China, Africa, Europe and North America ${ }^{3,26,27}$ - suggest that bat coronaviruses remain a substantial global threat to public health.

Finally, this study demonstrates the public health importance of pathogen discovery programs targeting wildlife that aim to identify the "known unknowns'-previously unknown viral strains closely related to known pathogens. These programs, focused on specific high-risk wildlife groups and hotspots of disease emergence, may be a critical part of future global strategies to predict, prepare for, and prevent pandemic emergence ${ }^{28}$.

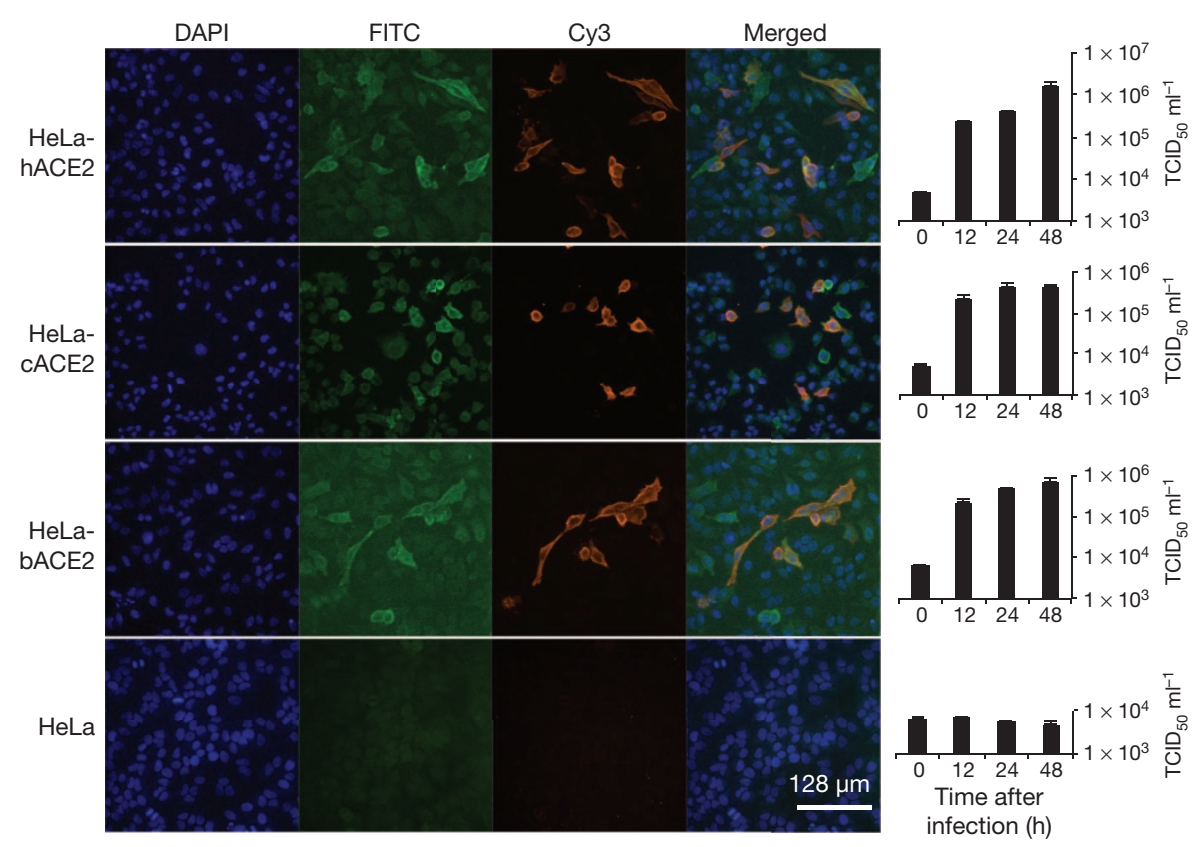

Figure 3 Analysis of receptor usage of SL-CoV-WIV1 determined by immunofluorescence assay and real-time PCR. Determination of virus infectivity in HeLa cells with and without the expression of ACE2. b, bat; c, civet; h, human. ACE2 expression was detected with goat anti-humanACE2 antibody followed by fluorescein isothiocyanate (FITC)-conjugated donkey anti-goat IgG. Virus replication was detected with rabbit antibody against the
SL-CoV Rp3 nucleocapsid protein followed by cyanine 3 (Cy3)-conjugated mouse anti-rabbit IgG. Nuclei were stained with DAPI (4',6-diamidino-2phenylindole). The columns (from left to right) show staining of nuclei (blue), ACE2 expression (green), virus replication (red), merged triple-stained images and real-time PCR results, respectively. $(n=3)$; error bars represent standard deviation. 


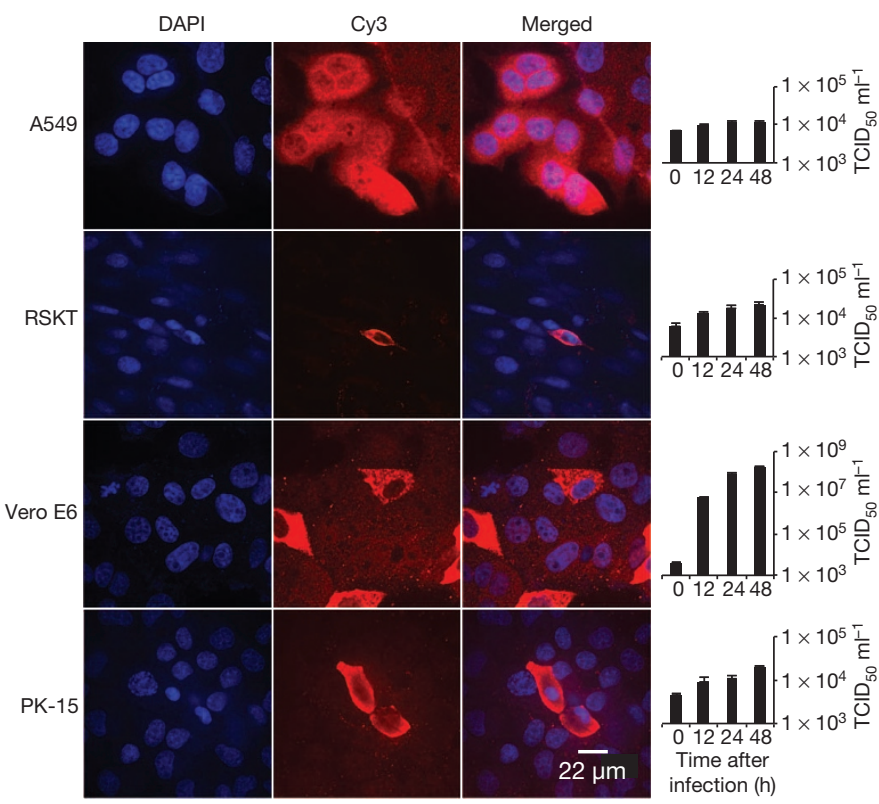

Figure $4 \mid$ Analysis of host range of SL-CoV-WIV1 determined by immunofluorescence assay and real-time PCR. Virus infection in A549, RSKT, Vero E6 and PK-15 cells. Virus replication was detected as described for Fig. 3. The columns (from left to right) show staining of nuclei (blue), virus replication (red), merged double-stained images and real-time PCR results, respectively. $n=3$; error bars represent s.d.

\section{METHODS SUMMARY}

Throat and faecal swabs or fresh faecal samples were collected in viral transport medium as described previously ${ }^{14}$. All PCR was conducted with the One-Step RTPCR kit (Invitrogen). Primers targeting the highly conserved regions of the RdRP gene were used for detection of all alphacoronaviruses and betacoronaviruses as described previously ${ }^{15}$. Degenerate primers were designed on the basis of all available genomic sequences of SARS-CoVs and SL-CoVs and used for amplification of the RBD sequences of $S$ genes or full-length genomic sequences. Degenerate primers were used for amplification of the bat ACE2 gene as described previously ${ }^{29}$. PCR products were gel purified and cloned into pGEM-T Easy Vector (Promega). At least four independent clones were sequenced to obtain a consensus sequence. PCRpositive faecal samples (in $200 \mu \mathrm{l}$ buffer) were gradient centrifuged at $3,000-12,000 \mathrm{~g}$ and supernatant diluted at 1:10 in DMEM before being added to Vero E6 cells. After incubation at $37^{\circ} \mathrm{C}$ for $1 \mathrm{~h}$, inocula were removed and replaced with fresh DMEM with $2 \%$ FCS. Cells were incubated at $37^{\circ} \mathrm{C}$ and checked daily for cytopathic effect. Cell lines from different origins were grown on coverslips in 24-well plates and inoculated with the novel SL-CoV at a multiplicity of infection of 10 . Virus replication was detected at $24 \mathrm{~h}$ after infection using rabbit antibodies against the SL$\mathrm{CoV} \mathrm{Rp} 3$ nucleocapsid protein followed by $\mathrm{Cy} 3$-conjugated goat anti-rabbit IgG.

Online Content Any additional Methods, Extended Data display items and Source Data are available in the online version of the paper; references unique to these sections appear only in the online paper.

\section{Received 16 May; accepted 18 September 2013.}

Published online 30 October 2013.

1. Ksiazek, T. G. et al. A novel coronavirus associated with severe acute respiratory syndrome. N. Engl. J. Med. 348, 1953-1966 (2003)

2. Zaki, A. M., van Boheemen, S., Bestebroer, T. M. Osterhaus, A. D. \& Fouchier, R. A. Isolation of a novel coronavirus from a man with pneumonia in Saudi Arabia. N. Engl. J. Med. 367, 1814-1820 (2012).

3. Anthony, S. J. etal. Coronaviruses in bats from Mexico.J. Gen. Virol. 94, 1028-1038(2013)

4. Raj, V. S. et al. Dipeptidyl peptidase 4 is a functional receptor for the emerging human coronavirus-EMC. Nature 495, 251-254 (2013).

5. Li, W. et al. Bats are natural reservoirs of SARS-like coronaviruses. Science $\mathbf{3 1 0}$, 676-679 (2005).

6. Drexler, J. F. et al. Genomic characterization of severe acute respiratory syndrome-related coronavirus in European bats and classification of coronaviruses based on partial RNA-dependent RNA polymerase gene sequences. J. Virol. 84, 11336-11349 (2010).

7. Tong, S. et al. Detection of novel SARS-like and other coronaviruses in bats from Kenya. Emerg. Infect. Dis. 15, 482-485 (2009).

8. Lau, S. K. P. et al. Severe acute respiratory syndrome coronavirus-like virus in Chinese horseshoe bats. Proc. Natl Acad. Sci. USA 102, 14040-14045 (2005).
9. Ren, W. et al. Difference in receptor usage between severe acute respiratory syndrome (SARS) coronavirus and SARS-like coronavirus of bat origin. J. Virol. 82, 1899-1907 (2008).

10. Hon, C. C. et al. Evidence of the recombinant origin of a bat severe acute respiratory syndrome (SARS)-like coronavirus and its implications on the direct ancestor of SARS coronavirus. J. Virol. 82, 1819-1826 (2008).

11. Li, W. et al. Angiotensin-converting enzyme 2 is a functional receptor for the SARS coronavirus. Nature 426, 450-454 (2003)

12. Wong, S. K., Li, W., Moore, M. J., Choe, H. \& Farzan, M. A 193-amino acid fragment of the SARS coronavirus $S$ protein efficiently binds angiotensin-converting enzyme 2. J. Biol. Chem. 279, 3197-3201 (2004)

13. Becker, M. M. et al. Synthetic recombinant bat SARS-like coronavirus is infectious in cultured cells and in mice. Proc. Natl Acad. Sci. USA 105, 19944-19949 (2008).

14. Li, Y. et al. Host range, prevalence, and genetic diversity of adenoviruses in bats. J. Virol. 84, 3889-3897 (2010).

15. De Souza Luna, L. K. et al. Generic detection of coronaviruses and differentiation at the prototype strain level by reverse transcription-PCR and nonfluorescent low-density microarray. J. Clin. Microbiol. 45, 1049-1052 (2007)

16. Cui, J. et al. Evolutionary relationships between bat coronaviruses and their hosts. Emerg. Infect. Dis. 13, 1526-1532 (2007).

17. Yuan, J. et al. Intraspecies diversity of SARS-like coronaviruses in Rhinolophus sinicus and its implications for the origin of SARS coronaviruses in humans. J. Gen. Virol. 91, 1058-1062 (2010).

18. Ren, W. et al. Full-length genome sequences of two SARS-like coronaviruses in horseshoe bats and genetic variation analysis. J. Gen. Virol. 87, 3355-3359 (2006).

19. Martin, D. P. et al. RDP3: a flexible and fast computer program for analyzing recombination. Bioinformatics 26, 2462-2463 (2010).

20. Wu, K., Peng, G., Wilken, M., Geraghty, R. J. \& Li, F. Mechanisms of host receptor adaptation by severe acute respiratory syndrome coronavirus. J. Biol. Chem. 287, 8904-8911 (2012).

21. Li, W. et al. Receptor and viral determinants of SARS-coronavirus adaptation to human ACE2. EMBO J. 24, 1634-1643 (2005).

22. Lau, S. K. et al. Ecoepidemiology and complete genome comparison of different strains of severe acute respiratory syndrome-related Rhinolophus bat coronavirus in China reveal bats as a reservoir for acute, self-limiting infection that allows recombination events. J. Virol. 84, 2808-2819 (2010).

23. Lau, S. K. et al. Coexistence of different genotypes in the same bat and serological characterization of Rousettus bat coronavirus HKU9 belonging to a novel Betacoronavirus subgroup. J. Virol. 84, 11385-11394 (2010).

24. Song, H. D. etal. Cross-host evolution of severe acute respiratory syndrome coronavirus in palm civet and human. Proc. Natl Acad. Sci. USA 102, 2430-2435 (2005).

25. Memish, Z. A. et al. Middle East respiratory syndrome coronavirus in bats, Saudi Arabia. Emerg. Infect. Dis. 19, 11 (2013).

26. Chan, J. F.etal. Is the discovery of the novel human betacoronavirus $2 \mathrm{C}$ EMC/2012 ( $\mathrm{HCoV}$ EMC) the beginning of another SARS-like pandemic? J. Infect. 65, 477-489 (2012).

27. Ithete, N. L. et al. Close relative of human Middle East respiratory syndrome coronavirus in bat, South Africa. Emerg. Infect. Dis. 19, 1697-1699 (2013).

28. Morse, S. S. et al. Prediction and prevention of the next pandemic zoonosis. Lancet 380, 1956-1965 (2012)

29. Hou, Y. et al. Angiotensin-converting enzyme 2 (ACE2) proteins of different bat species confer variable susceptibility to SARS-CoV entry. Arch. Virol. 155, 1563-1569 (2010)

Acknowledgements We acknowledge financial support from the State Key Program for Basic Research (2011CB504701 and 2010CB530100), National Natural Science Foundation of China (81290341 and 31321001), Scientific and technological basis special project (2013FY113500), CSIRO OCE Science Leaders Award, National Institute of Allergy and Infectious Diseases (NIAID) award number R01AI079231, a National Institutes of Health (NIH)/National Science Foundation (NSF) 'Ecology and Evolution of Infectious Diseases' award from the NIH Fogarty International Center (R01TW005869), an award from the NIH Fogarty International Center supported by International Influenza Funds from the Office of the Secretary of the Department of Health and Human Services (R56TW009502), and United States Agency for International Development (USAID) Emerging Pandemic Threats PREDICT. The contents are the responsibility of the authors and do not necessarily reflect the views of NIAID, NIH, NSF, USAID or the United States Government. We thank X. Che from Zhujiang Hospital, Southern Medical University, for providing human SARS patient sera.

Author Contributions Z.-L.S. and P.D. designed and coordinated the study. X.-Y.G., J.-L. L. and X.-L.Y. conducted majority of experiments and contributed equally to the study. A.A.C., B.H., W.Z., C.P., Y.-J.Z., C.-M.L., B.T., N.W. and Y.Z. conducted parts of the experiments and analyses. J.H.E., J.K.M. and S.-Y.Z. coordinated the field study. X.-Y.G. J.-L.L., X.-L.Y., B.T. and G.-J.Z. collected the samples. G.C. and L.-F.W. designed and supervised part of the experiments. All authors contributed to the interpretations and conclusions presented. Z.-L.S. and X-Y.G. wrote the manuscript with significant contributions from P.D. and L-F.W. and input from all authors.

Author Information Sequences of three bat SL-CoV genomes, bat SL-CoV RBD and $R$. sinicus ACE2 genes have been deposited in GenBank under accession numbers KC881005-KC881007 (genomes from SL-CoV RsSHC014, Rs3367 and W1V1, respectively), KC880984-KC881003 (bat SL-CoV RBD genes) and KC881004 (R. sinicus ACE2), respectively. Reprints and permissions information is available at www.nature.com/reprints. The authors declare no competing financial interests. Readers are welcome to comment on the online version of the paper. Correspondence and requests for materials should be addressed to P.D.

(daszak@ecohealthalliance.org) or Z.-L.S. (zlshi@wh.iov.cn). 


\section{METHODS}

Sampling. Bats were trapped in their natural habitat as described previously ${ }^{5}$. Throat and faecal swab samples were collected in viral transport medium (VTM) composed of Hank's balanced salt solution, pH 7.4, containing BSA (1\%), amphotericin $\left(15 \mu \mathrm{g} \mathrm{ml}^{-1}\right)$, penicillin $\mathrm{G}\left(100 \mathrm{U} \mathrm{ml}^{-1}\right)$ and streptomycin $\left(50 \mu \mathrm{g} \mathrm{ml}^{-1}\right)$. To collect fresh faecal samples, clean plastic sheets measuring 2.0 by $2.0 \mathrm{~m}$ were placed under known bat roosting sites at about 18:00 h each evening. Relatively fresh faecal samples were collected from sheets at approximately 05:30-06:00 the next morning and placed in VTM. Samples were transported to the laboratory and stored at $-80^{\circ} \mathrm{C}$ until use. All animals trapped for this study were released back to their habitat after sample collection. All sampling processes were performed by veterinarians with approval from Animal Ethics Committee of the Wuhan Institute of Virology (WIVH05210201) and EcoHealth Alliance under an inter-institutional agreement with University of California, Davis (UC Davis protocol no. 16048). RNA extraction, PCR and sequencing. RNA was extracted from $140 \mu \mathrm{l}$ of swab or faecal samples with a Viral RNA Mini Kit (Qiagen) following the manufacturer's instructions. RNA was eluted in $60 \mu \mathrm{l}$ RNAse-free buffer (buffer AVE, Qiagen), then aliquoted and stored at $-80^{\circ} \mathrm{C}$. One-step RT-PCR (Invitrogen) was used to detect coronavirus sequences as described previously ${ }^{15}$. First round PCR was conducted in a $25-\mu \mathrm{l}$ reaction mix containing $12.5 \mu \mathrm{l}$ PCR $2 \times$ reaction mix buffer, 10 pmol of each primer, $2.5 \mathrm{mM} \mathrm{MgSO} 4,20 \mathrm{U}$ RNase inhibitor, $1 \mu \mathrm{l}$ SuperScript III/ Platinum Taq Enzyme Mix and $5 \mu$ RNA. Amplification of the RdRP-gene fragment was performed as follows: $50^{\circ} \mathrm{C}$ for $30 \mathrm{~min}, 94^{\circ} \mathrm{C}$ for $2 \mathrm{~min}$, followed by 40 cycles consisting of $94^{\circ} \mathrm{C}$ for $15 \mathrm{~s}, 62^{\circ} \mathrm{C}$ for $15 \mathrm{~s}, 68^{\circ} \mathrm{C}$ for $40 \mathrm{~s}$, and a final extension of $68^{\circ} \mathrm{C}$ for $5 \mathrm{~min}$. Second round PCR was conducted in a $25-\mu \mathrm{l}$ reaction mix containing $2.5 \mu \mathrm{l}$ PCR reaction buffer, $5 \mathrm{pmol}$ of each primer, $50 \mathrm{mM} \mathrm{MgCl}$, $0.5 \mathrm{mM}$ dNTP, $0.1 \mu \mathrm{l}$ Platinum Taq Enzyme (Invitrogen) and $1 \mu \mathrm{l}$ first round PCR product. The amplification of RdRP-gene fragment was performed as follows: $94{ }^{\circ} \mathrm{C}$ for $5 \mathrm{~min}$ followed by 35 cycles consisting of $94{ }^{\circ} \mathrm{C}$ for $30 \mathrm{~s}, 52^{\circ} \mathrm{C}$ for $30 \mathrm{~s}, 72{ }^{\circ} \mathrm{C}$ for $40 \mathrm{~s}$, and a final extension of $72{ }^{\circ} \mathrm{C}$ for $5 \mathrm{~min}$.

To amplify the RBD region, one-step RT-PCR was performed with primers designed based on available SARS-CoV or bat SL-CoVs (first round PCR primers; F, forward; R, reverse: CoVS931F-5'-VWGADGTTGTKAGRTTYCCT-3' and CoVS1909R-5' -TAARACAVCCWGCYTGWGT-3'; second PCR primers: CoVS 951F-5' -TGTKAGRTTYCCTAAYATTAC- ${ }^{\prime}$ and CoVS1805R-5' ${ }^{\prime}$-ACATCYTG ATANARAACAGC- $3^{\prime}$ ). First-round PCR was conducted in a $25-\mu$ reaction mix as described above except primers specific for the $S$ gene were used. The amplification of the RBD region of the $S$ gene was performed as follows: $50^{\circ} \mathrm{C}$ for $30 \mathrm{~min}$, $94{ }^{\circ} \mathrm{C}$ for $2 \mathrm{~min}$, followed by 35 cycles consisting of $94{ }^{\circ} \mathrm{C}$ for $15 \mathrm{~s}, 43^{\circ} \mathrm{C}$ for $15 \mathrm{~s}$, $68^{\circ} \mathrm{C}$ for $90 \mathrm{~s}$, and a final extension of $68^{\circ} \mathrm{C}$ for $5 \mathrm{~min}$. Second-round PCR was conducted in a $25-\mu \mathrm{l}$ reaction mix containing $2.5 \mu \mathrm{l} \mathrm{PCR}$ reaction buffer, $5 \mathrm{pmol}$ of each primer, $50 \mathrm{mM} \mathrm{MgCl}_{2}, 0.5 \mathrm{mM} \mathrm{dNTP,} 0.1 \mu \mathrm{l}$ Platinum Taq Enzyme (Invitrogen) and $1 \mu \mathrm{l}$ first round PCR product. Amplification was performed as follows: $94^{\circ} \mathrm{C}$ for 5 min followed by 40 cycles consisting of $94^{\circ} \mathrm{C}$ for $30 \mathrm{~s}, 41^{\circ} \mathrm{C}$ for $30 \mathrm{~s}, 72^{\circ} \mathrm{C}$ for $60 \mathrm{~s}$, and a final extension of $72{ }^{\circ} \mathrm{C}$ for $5 \mathrm{~min}$.

PCR products were gel purified and cloned into pGEM-T Easy Vector (Promega). At least four independent clones were sequenced to obtain a consensus sequence for each of the amplified regions.

Sequencing full-length genomes. Degenerate coronavirus primers were designed based on all available SARS-CoV and bat SL-CoV sequences in GenBank and specific primers were designed from genome sequences generated from previous rounds of sequencing in this study (primer sequences will be provided upon request). All PCRs were conducted using the One-Step RT-PCR kit (Invitrogen). The $5^{\prime}$ and $3^{\prime}$ genomic ends were determined using the $5^{\prime}$ or $3^{\prime}$ RACE kit (Roche), respectively. PCR products were gel purified and sequenced directly or following cloning into pGEM-T Easy Vector (Promega). At least four independent clones were sequenced to obtain a consensus sequence for each of the amplified regions and each region was sequenced at least twice.

Sequence analysis and databank accession numbers. Routine sequence management and analysis was carried out using DNAStar or Geneious. Sequence alignment and editing was conducted using ClustalW, BioEdit or GeneDoc. Maximum Likelihood phylogenetic trees based on the protein sequences were constructed using a Poisson model with bootstrap values determined by 1,000 replicates in the MEGA5 software package.

Sequences obtained in this study have been deposited in GenBank as follows (accession numbers given in parenthesis): full-length genome sequence of SL-CoV RsSHC014 and Rs3367 (KC881005, KC881006); full-length sequence of WIV1 S (KC881007); RBD (KC880984-KC881003); ACE2 (KC8810040). SARS-CoV sequences used in this study: human SARS-CoV strains Tor2 (AY274119), BJ01 (AY278488), GZ02 (AY390556) and civet SARS-CoV strain SZ3 (AY304486). Ba coronavirus sequences used in this study: Rs672 (FJ588686), Rp3 (DQ071615), Rf1 (DQ412042), Rm1 (DQ412043), HKU3-1 (DQ022305), BM48-31 (NC_014470), HKU9-1 (NC_009021), HKU4 (NC_009019), HKU5 (NC_009020), HKU8 (DQ249228),
HKU2 (EF203067), BtCoV512 (NC_009657), 1A (NC_010437). Other coronavirus sequences used in this study: $\mathrm{HCoV}-229 \mathrm{E}$ (AF304460), HCoV-OC43 (AY391777), HCoV-NL63 (AY567487), HKU1 (NC_006577), EMC (JX869059), FIPV (NC_002306), PRCV (DQ811787), BWCoV (NC_010646), MHV (AY700211), IBV (AY851295).

Amplification, cloning and expression of the bat ACE2 gene. Construction of expression clones for human and civet ACE2 in pcDNA3.1 has been described previously ${ }^{29}$. Bat ACE2 was amplified from a $R$. sinicus (sample no. 3357). In brief, total RNA was extracted from bat rectal tissue using the RNeasy Mini Kit (Qiagen). First-strand complementary DNA was synthesized from total RNA by reverse transcription with random hexamers. Full-length bat ACE2 fragments were amplified using forward primer bAF2 and reverse primer bAR2 (ref. 29). The ACE2 gene was cloned into pCDNA3.1 with KpnI and XhoI, and verified by sequencing. Purified ACE2 plasmids were transfected to HeLa cells. After $24 \mathrm{~h}$, lysates of HeLa cells expressing human, civet, or bat ACE2 were confirmed by western blot or immunofluorescence assay.

Western blot analysis. Lysates of cells or filtered supernatants containing pseudoviruses were separated by SDS-PAGE, followed by transfer to a nitrocellulose membrane (Millipore). For detection of $S$ protein, the membrane was incubated with rabbit anti-Rp3 S fragment (amino acids 561-666) polyantibodies (1:200), and the bound antibodies were detected by alkaline phosphatase (AP)-conjugated goat anti-rabbit IgG $(1: 1,000)$. For detection of HIV-1 p24 in supernatants, monoclonal antibody against HIV p24 (p24 MAb) was used as the primary antibody at a dilution of 1:1,000, followed by incubation with AP-conjugated goat anti-mouse IgG at the same dilution. To detect the expression of ACE2 in HeLa cells, goat antibody against the human ACE2 ectodomain (1:500) was used as the first antibody, followed by incubation with horseradish peroxidase-conjugated donkey anti-goat IgG $(1: 1,000)$. Virus isolation. Vero E6 cell monolayers were maintained in DMEM supplemented with $10 \%$ FCS. PCR-positive samples (in $200 \mu \mathrm{l}$ buffer) were gradient centrifuged at 3,000-12,000g, and supernatant were diluted 1:10 in DMEM before being added to Vero E6 cells. After incubation at $37^{\circ} \mathrm{C}$ for $1 \mathrm{~h}$, inocula were removed and replaced with fresh DMEM with $2 \%$ FCS. Cells were incubated at $37^{\circ} \mathrm{C}$ for 3 days and checked daily for cytopathic effect. Double-dose triple antibiotics penicillin/ streptomycin/amphotericin (Gibco) were included in all tissue culture media (penicillin $200 \mathrm{IU} \mathrm{ml}^{-1}$, streptomycin $0.2 \mathrm{mg} \mathrm{ml}^{-1}$, amphotericin $0.5 \mu \mathrm{g} \mathrm{ml}^{-1}$ ). Three blind passages were carried out for each sample. After each passage, both the culture supernatant and cell pellet were examined for presence of virus by RT-PCR using primers targeting the RdRP or $S$ gene. Virions in supernatant $(10 \mathrm{ml})$ were collected and fixed using $0.1 \%$ formaldehyde for $4 \mathrm{~h}$, then concentrated by ultracentrifugation through a $20 \%$ sucrose cushion $(5 \mathrm{ml})$ at $80,000 \mathrm{~g}$ for 90 min using a Ty 90 rotor (Beckman). The pelleted viral particles were suspended in $100 \mu \mathrm{l}$ PBS, stained with $2 \%$ phosphotungstic acid ( $\mathrm{pH} 7.0)$ and examined using a Tecnai transmission electron microscope (FEI) at $200 \mathrm{kV}$.

Virus infectivity detected by immunofluorescence assay. Cell lines used for this study and their culture conditions are summarized in Extended Data Table 5. Virus titre was determined in Vero E6 cells by cytopathic effect (CPE) counts. Cell lines from different origins and HeLa cells expressing ACE2 from human, civet or Chinese horseshoe bat were grown on coverslips in 24-well plates (Corning) incubated with bat SL-CoV-WIV1 at a multiplicity of infection $=10$ for $1 \mathrm{~h}$. The inoculum was removed and washed twice with PBS and supplemented with medium. HeLa cells without ACE2 expression and Vero E6 cells were used as negative and positive controls, respectively. At $24 \mathrm{~h}$ after infection, cells were washed with PBS and fixed with $4 \%$ formaldehyde in PBS (pH 7.4) for 20 min at $4{ }^{\circ} \mathrm{C}$. ACE2 expression was detected using goat anti-human ACE2 immunoglobulin (R\&D Systems) followed by FITC-labelled donkey anti-goat immunoglobulin (PTGLab). Virus replication was detected using rabbit antibody against the SL-CoV Rp3 nucleocapsid protein followed by Cy3-conjugated mouse anti-rabbit IgG. Nuclei were stained with DAPI. Staining patterns were examined using a FV1200 confocal microscope (Olympus). Virus infectivity detected by real-time RT-PCR. Vero E6, A549, PK15, RSKT and HeLa cells with or without expression of ACE2 of different origins were inoculated with $0.1 \mathrm{TCID}_{50}$ WIV-1 and incubated for $1 \mathrm{~h}$ at $37^{\circ} \mathrm{C}$. After removing the inoculum, the cells were cultured with medium containing $1 \%$ FBS. Supernatants were collected at $0,12,24$ and $48 \mathrm{~h}$. RNA from $140 \mu \mathrm{l}$ of each supernatant was extracted with the Viral RNA Mini Kit (Qiagen) following manufacturer's instructions and eluted in $60 \mu \mathrm{l}$ buffer AVE (Qiagen). RNA was quantified on the ABI StepOne system, with the TaqMan AgPath-ID One-Step RT-PCR Kit (Applied Biosystems) in a $25 \mu \mathrm{l}$ reaction mix containing $4 \mu \mathrm{l}$ RNA, $1 \times$ RT-PCR enzyme mix, $1 \times$ RT-PCR buffer, 40 pmol forward primer (5'-GTGGTGGTGACGGCA AAATG- $\left.3^{\prime}\right), 40$ pmol reverse primer $\left(5^{\prime}\right.$-AAGTGAAGCTTCTGGGCCAG- $\left.3^{\prime}\right)$ and 12 pmol probe (5'-FAM-AAAGAGCTCAGCCCCAGATG-BHQ1-3'). Amplification parameters were $10 \mathrm{~min}$ at $50^{\circ} \mathrm{C}, 10 \mathrm{~min}$ at $95^{\circ} \mathrm{C}$ and 50 cycles of $15 \mathrm{~s}$ at $95^{\circ} \mathrm{C}$ and $20 \mathrm{~s}$ at $60^{\circ} \mathrm{C}$. RNA dilutions from purified WIV-1 stock were used as a standard. Serum neutralization test. SARS patient sera were inactivated at $56^{\circ} \mathrm{C}$ for $30 \mathrm{~min}$ and then used for virus neutralization testing. Sera were diluted starting with 1:10 


\section{RESEARCH LETTER}

and then serially twofold diluted in 96-well cell plates to 1:40. Each $100 \mu \mathrm{l}$ serum dilution was mixed with $100 \mu \mathrm{l}$ viral supernatant containing 100 TCID $5_{0}$ of WIV 1 and incubated at $37^{\circ} \mathrm{C}$ for $1 \mathrm{~h}$. The mixture was added in triplicate wells of 96 -well cell plates with plated monolayers of Vero E6 cells and further incubated at $37^{\circ} \mathrm{C}$ for 2 days. Serum from a healthy blood donor was used as a negative control in each experiment. CPE was observed using an inverted microscope 2 days after inoculation. The neutralizing antibody titre was read as the highest dilution of serum which completely suppressed CPE in infected wells. The neutralization test was repeated twice.

Recombination analysis. Full-length genomic sequences of SL-CoV Rs3367 or RsSHC014 were aligned with those of selected SARS-CoVs and bat SL-CoVs using Clustal X. The aligned sequences were preliminarily scanned for recombination events using Recombination Detection Program (RDP) 4.0 (ref. 19). The potential recombination events suggested by RDP owing to their strong $P$ values $(<10-20)$ were investigated further by similarity plot and bootscan analyses implemented in Simplot 3.5.1. Phylogenetic origin of the major and minor parental regions of Rs3367 or RsSHC014 were constructed from the concatenated sequences of the essential ORFs of the major and minor parental regions of selected SARS-CoV and SL-CoVs. Two genome regions between three estimated breakpoints $(20,827-$ 26,553 and 26,554-28,685) were aligned independently using ClustalX and generated two alignments of 5,727 base pairs and 2,133 base pairs. The two alignments were used to construct maximum likelihood trees to better infer the fragment parents. All nucleotide numberings in this study are based on Rs3367 genome position. 
Human SARS-COV GZ02 Human SARS-COV BJOI Human SARS-COV Tor2 Clvet SARS-COV SZ3 Bat SL-CoV Rs3367 Bat SL-CoV RsSHC014 Bat SL-CoV Rs3369 Bat SL-CoV Rs4075 Bat SL-CoV Rs4081 Bat SL-CoV Rs4085 Bat SL-CoV Rs4108 Bat SL-CoV Rs672 Bat SL-CoV Rf Bat SL-CoV Rp3 Bat SL-CoV Rm1

Bat SL-COV HKU3-1

Bat SARS-related CoV BM48-31

Human SARS-COV GZO2 Human SARS-COV BJ01 Human SARS-COV Tor2 Civet SARS-CoV SZ Bat SL-CoV Rs3367 Bat SL-CoV RsSHC014 Bat SL-CoV Rs3369 Bat SL-CoV Rs4075 Bat SL-CoV Rs4085 Bat SL-CoV Rs4108 Bat SL-CoV Rs672 Bat SL-CoV Rf Bat SL-CoV Rp3 Bat SL-CoV Rm1
Bat SL-COV HKU3-1 Bat SARS-related CoV BM48-31

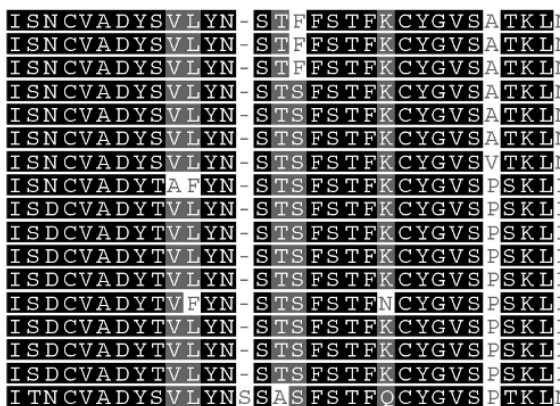

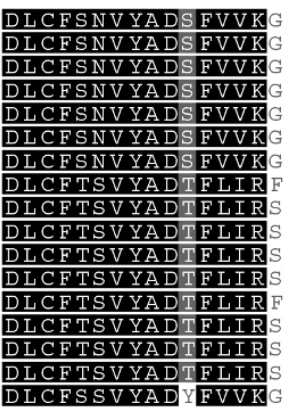

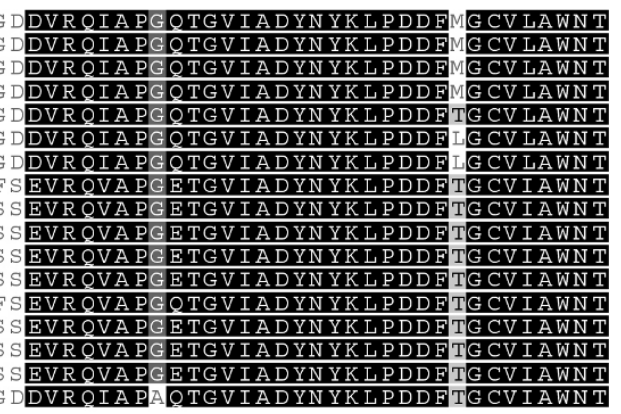

$\stackrel{n}{n}$

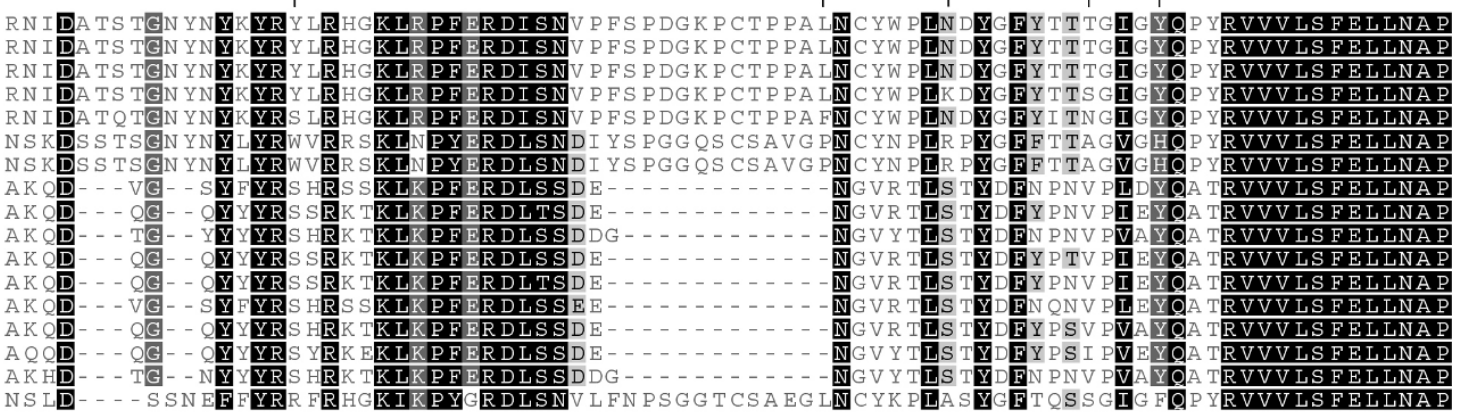

Human SARS-CoV GZO2 Human SARS-COV BJO1 Human SARS-COV Tor2 Civet SARS-COV SZ3 Bat SL-CoV Rs3367 Bat SL-CoV RsSHCO14 Bat SL-CoV Rs3369 Bat SL-CoV Rs4075 Bat SL-CoV Rs4081 Bat SL-CoV Rs 4085 Bat SL-CoV Rs4108 Bat SL-Cov Rs672 Bat SL-CoV Rf Bat SL-CoV Rp Bat SL-CoV Rm1 Bat SL-COV HKU3-1 Bat SARS-related CoV BM48-31

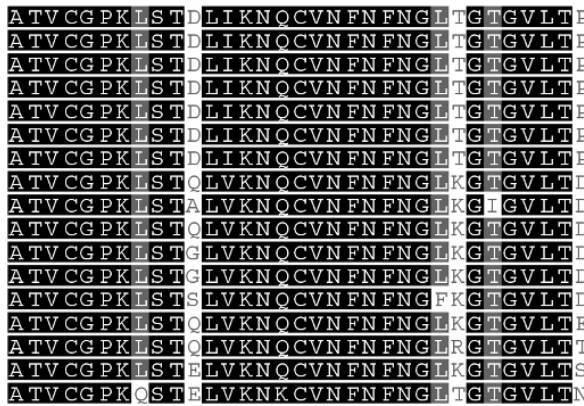

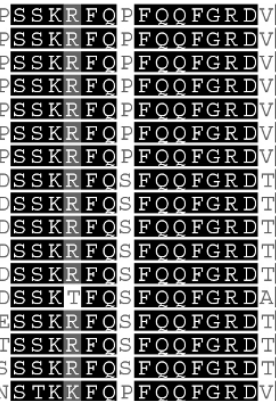

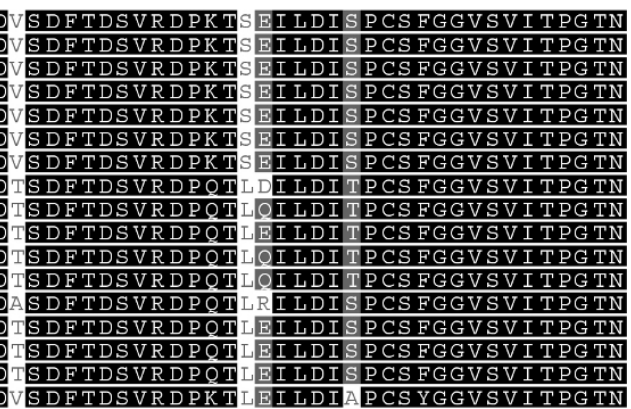

Extended Data Figure $1 \mid$ Sequence alignment of CoV S protein RBD. SARS-CoV S protein (amino acids 310-520) is aligned with homologous regions of bat SL-CoVs using ClustalW. The newly discovered bat SL-CoVs are indicated with a bold vertical line on the left. The key amino acid residues involved in the interaction with human ACE2 are numbered on the top of the aligned sequences. 


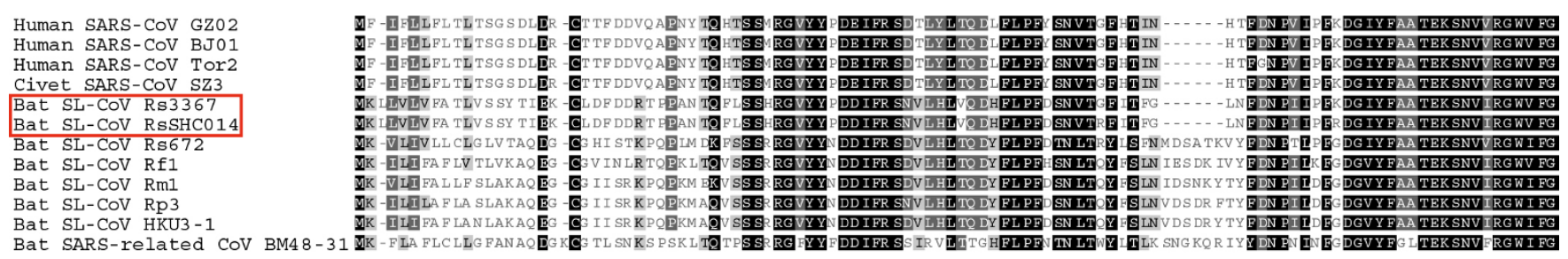

Human SARS-COV GZ02 Human SARS-COV BJOI Human SARS-COV Tor2 Civet SARS-CoV SZ3 Bat SL-CoV RsSHC014 Bat SL-CoV Rs672 Bat SL-CoV Rf Bat SL-CoV Rm1 Bat SL-CoV Rp3

Bat SL-COV HKU3 -

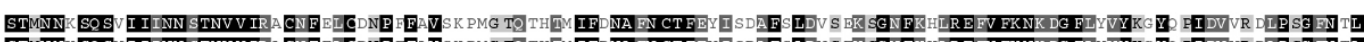

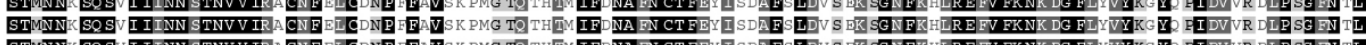

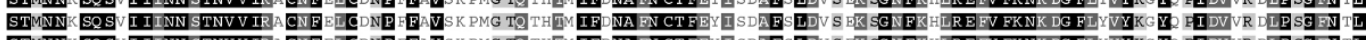

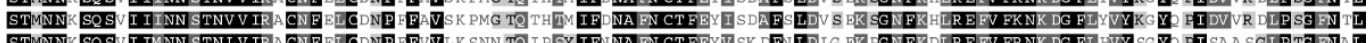

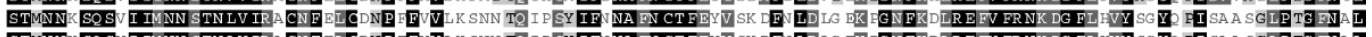

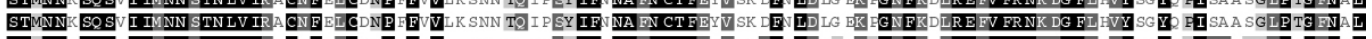

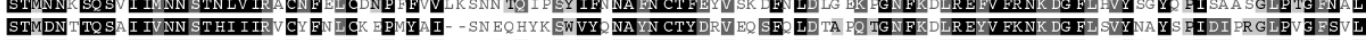

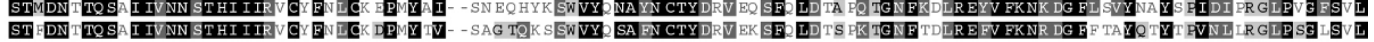

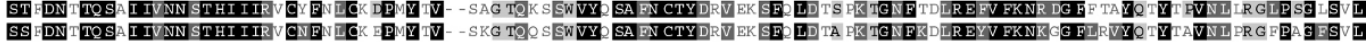

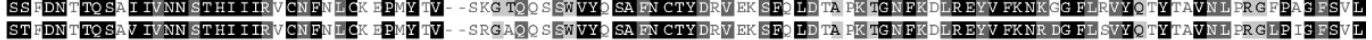

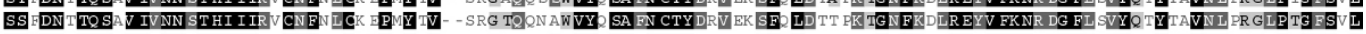

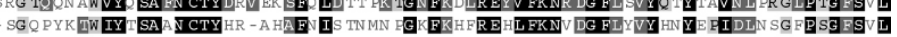

Human SARS-COV GZO2 Human SARS-COV BJ01 Human SARS-COV Tor2 Civet SARS-CoV SZ3 Bat SL-COV Rs3367
Bat SL-CoV RsSHCO14 Bat SL-CoV Rs672 Bat SL-CoV Rf Bat SL-CoV Rm1 Bat SL-COV Rp3 Bat SL-COV HKU3-1
Bat SARS-related CoV BM4 8-31 KPILLLEF IN ITSYRV VMAMES
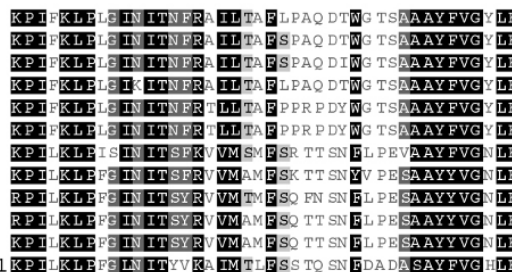

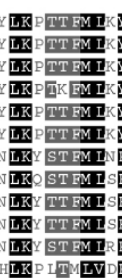

DENG TI T TAV DC SQN PLAE LK CSVK SE IDKG IYQT SN FR VV PSR DVVR FPN I TNICPEF EV DENG TI TDAV DC SQN PLAE LK CSVK SF TDKG IYQT SN FRVV TSS DVVR FPNI TNICPF EV EV

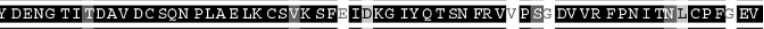
DENG TI TDAV DC SQN PLAE LK CSVK SF IDLKG IY QT SN FRV V SSG DVVR FPN I TN ICP F EV DENG TI TDAV DC SQN PLA E LK CSVK SE IDKG IYQT SN FR VA TSK EV VR FPN I TN ICP F EV

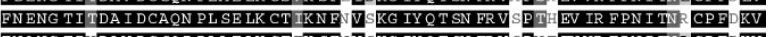

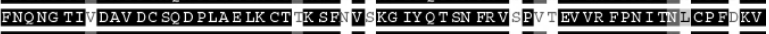

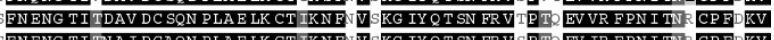

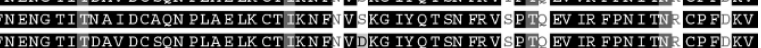

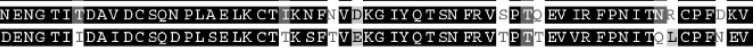

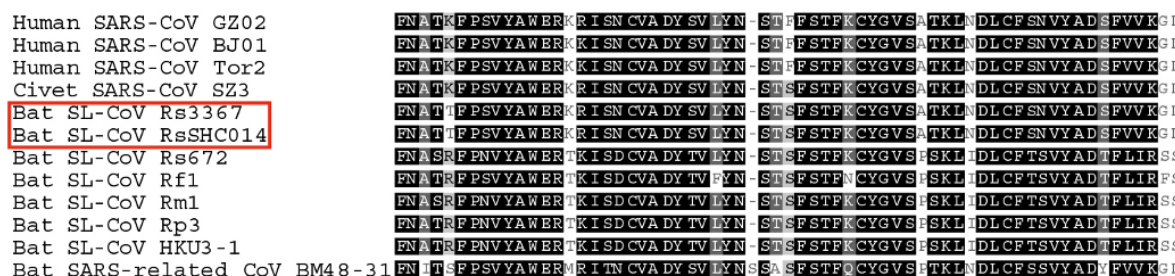

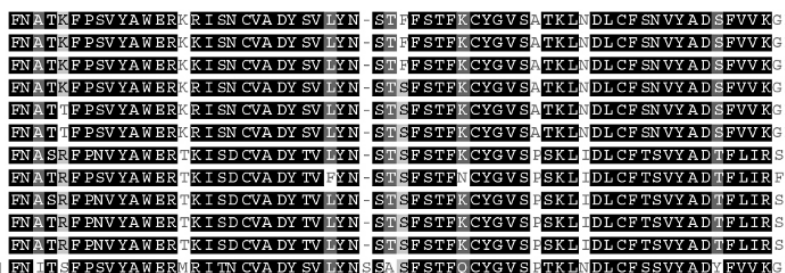

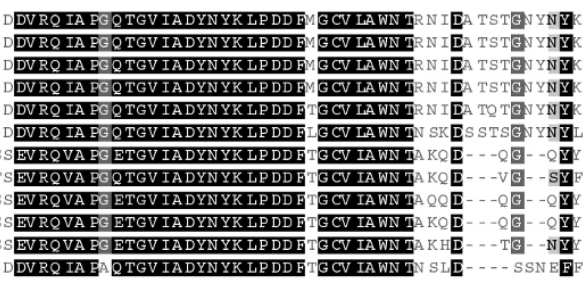

Human SARS-COV GZ02 Human SARS-COV BJO1 Human SARS-COV Tor2 Civet SARS-COV SZ3 $\begin{array}{ll}\text { Bat } & \text { SL-COV Rs3367 } \\ \text { Bat SL-CoV RsSHC014 }\end{array}$ Bat SL-CoV Rf Bat SL-COV Rm1 Bat SL-COV Rp3
Bat SL-COV HKU3-1

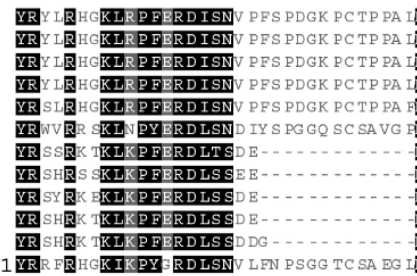

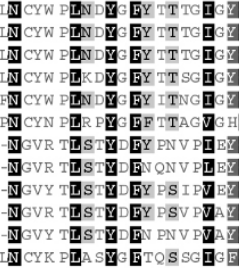

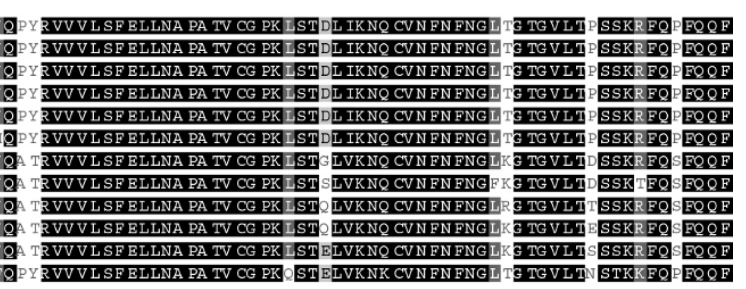

Human SARS-COV GZ02 Human SARS-COV BJOI Human SARS-COV Tor2 Civet SARS-COV SZ3
Bat SL-COV Rs3367 \begin{tabular}{ll} 
Bat SL-COV RsSHC014 \\
\hline Bat SL-COV Rs672
\end{tabular} Bat SL-CoV Rf Bat SL-CoV Rmi Bat SL-CoV Rp Bat SL-COV HKU3-1 Bat SARS-related COV BM48-31

Extended Data Figure $2 \mid$ Alignment of CoV S protein S1 sequences. Alignment of S1 sequences (amino acids 1-660) of the two novel bat SL-CoV S proteins with those of previously reported bat SL-CoVs and human and civet SARS-CoVs. The newly discovered bat SL-CoVs are boxed in red. SARS-CoV GZ02, BJ01 and Tor2 were isolated from patients in the early, middle and late phase, respectively, of the SARS outbreak in 2003. SARS-CoV

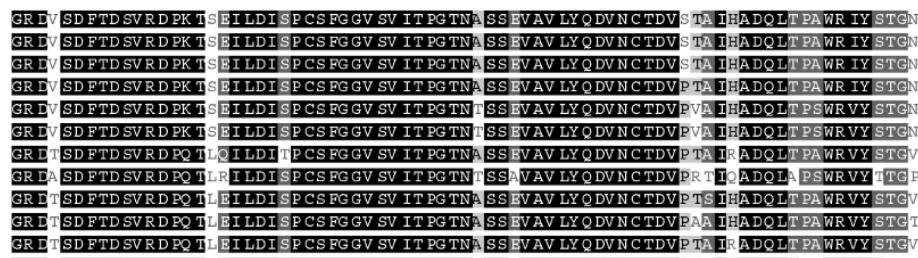

WVFOTQA G CLIGA EHV DT SY ECDI PIGAG ICASY - VVFQ TQA G CLIGA EHV D SY ECDI PIGAG ICA SYH - WVEQTQA GCLIGA EHV D SY ECDI PIGAG ICA SYH VFO TQA GCLIGA EHV D SY ECDI PIGAG ICA SYH VV FO TQA G CLIGA EHV D SY ECDI PIGAG ICA SY H -IVFQ TQA GCLIGA EHV DT SY ECDI PIGAG ICA SYH WVFQ TQA GCLIGA EHVN SY ECDI PIGAG ICASYH -Y VFOTOA G C LIGA SHVN SYOCDI PIGAG ICA SYH WVFO TOA GCLIGA EHV N SY ECDI PIGAG ICA SYH NVFQTQA GCLIGA EHVN SY ECDI PIGAG ICA SYH

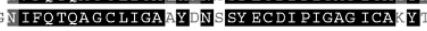

SZ3 was identified from P. larvata in 2003 collected in Guangdong, China. SL-CoV Rp3, Rs 672 and HKU3-1 were identified from $R$. sinicus collected in Guangxi, Guizhou and Hong Kong, China, respectively. Rf1 and Rm1 were identified from $R$. ferrumequinum and $R$. macrotis, respectively, collected in Hubei Province, China. Bat SARS-related CoV BM48-31 was identified from R. blasii collected in Bulgaria. 


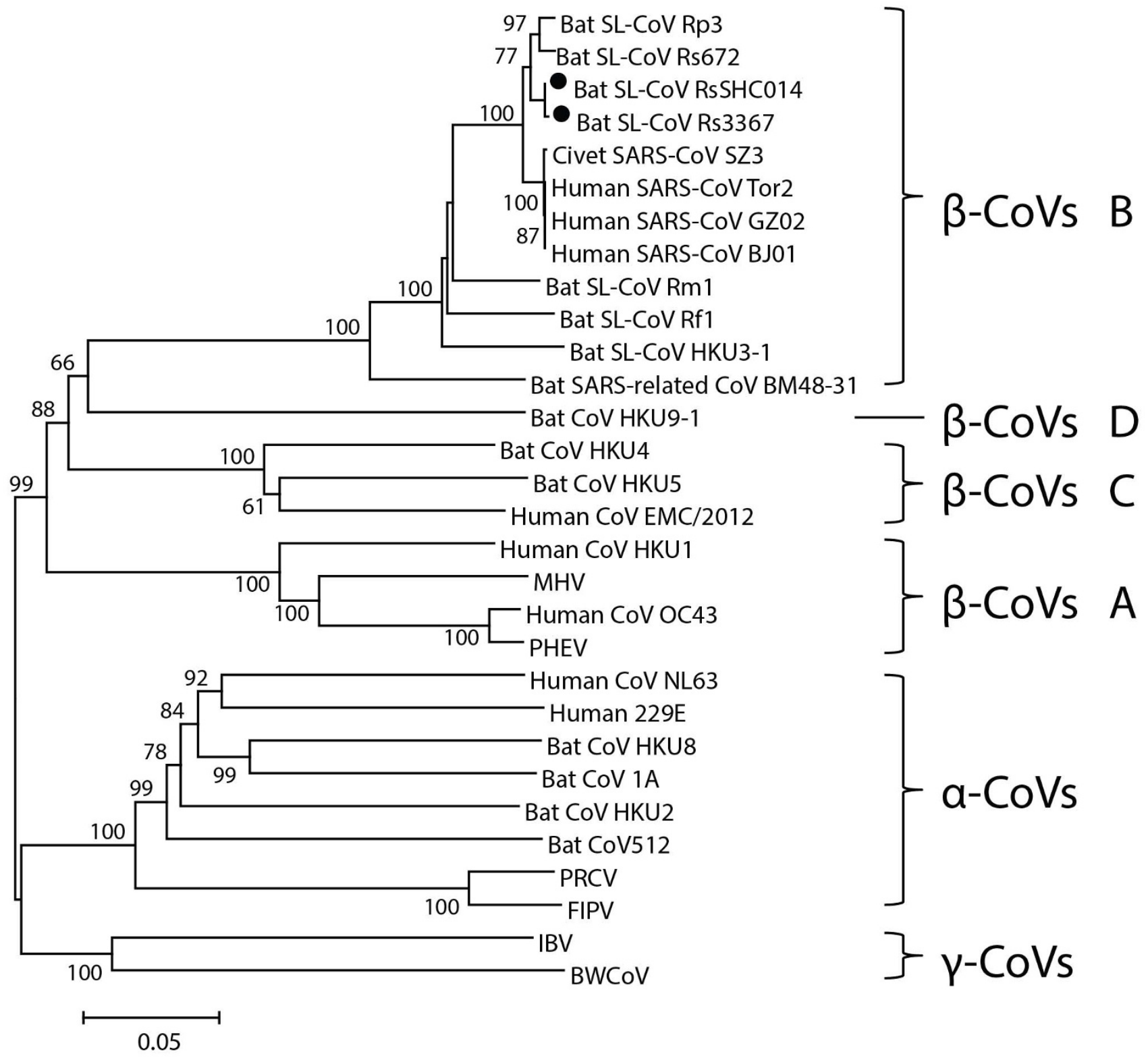

Extended Data Figure 3 Complete RdRP sequence phylogeny.

Phylogenetic tree of bat SL-CoVs and SARS-CoVs on the basis of complete RdRP sequences (2,796 nucleotides). Bat SL-CoVs RsSHC014 and Rs3367 are highlighted by filled circles. Three established coronaivirus genera, Alphacoronavirus, Betacoronavirus and Gammacoronavirus are marked as $\alpha, \beta$ and $\gamma$, respectively. Four $\mathrm{CoV}$ groups in the genus Betacoronavirus are indicated as $\mathrm{A}, \mathrm{B}, \mathrm{C}$ and $\mathrm{D}$, respectively. $\mathrm{MHV}$, murine hepatitis virus; PHEV, porcine haemagglutinating encephalomyelitis virus; PRCV, porcine respiratory coronavirus; FIPV, feline infectious peritonitis virus; IBV, infectious bronchitis coronavirus; BW, beluga whale coronavirus. 


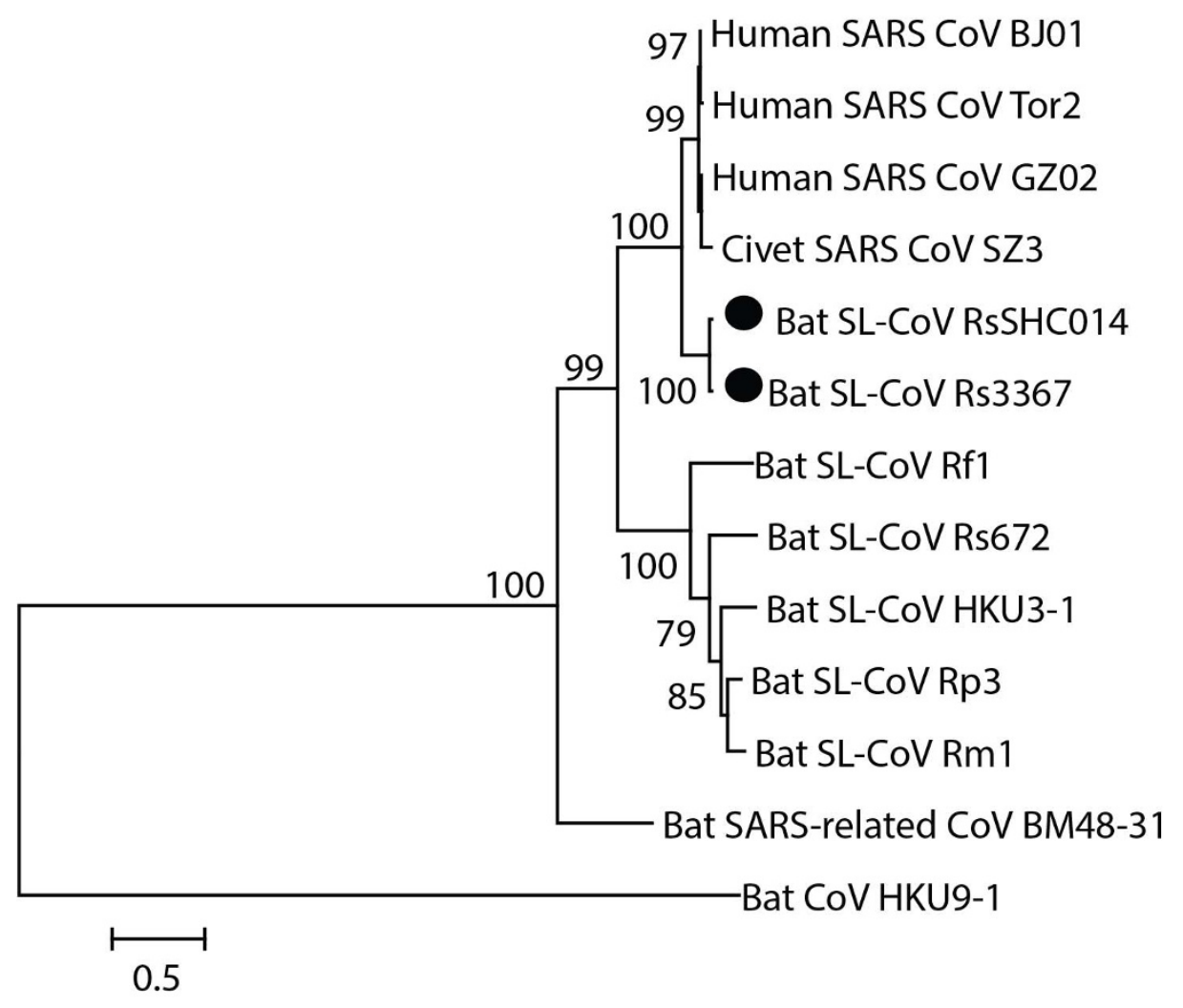

Extended Data Figure $4 \mid$ Sequence phylogeny of the complete $S$ protein of

Bat SL-CoVs RsSHC014 and Rs3367 are highlighted by filled circles. Bat CoV SL-CoVs and SARS-CoV. Phylogenetic tree of bat SL-CoVs and SARS-CoVs HKU9 was used as an outgroup. on the basis of complete $S$ protein sequences (1,256 amino acids). 
a
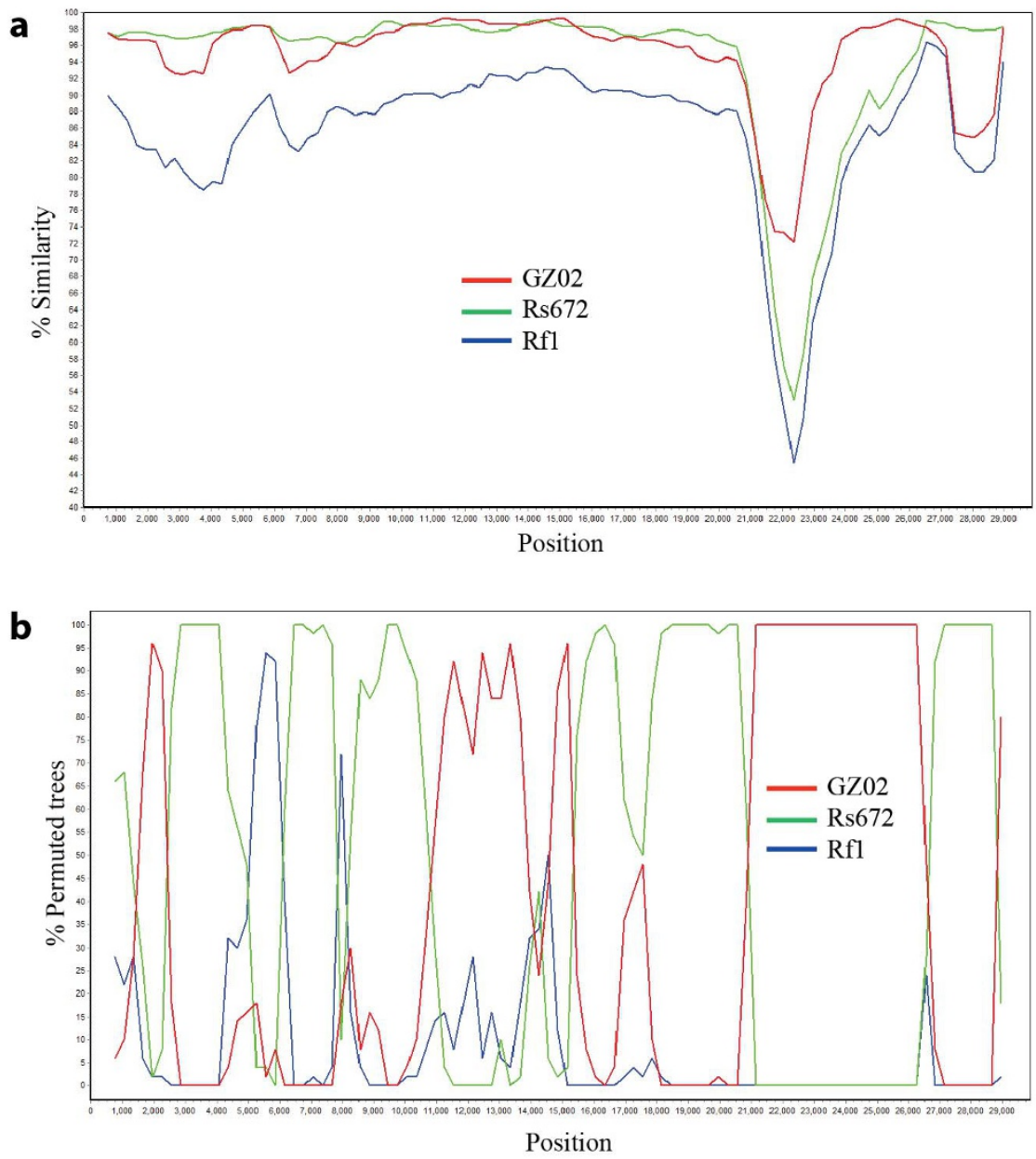

Extended Data Figure $5 \mid$ Detection of potential recombination events. $\mathbf{a}, \mathbf{b}$, Similarity plot (a) and bootscan analysis (b) detected three recombination breakpoints in the bat SL-CoV Rs3367 or SHC014 genome. The three breakpoints were located at the ORF1b (nt 20,827), M (nucleotides 26,553) and
$\mathrm{N}$ (nucleotides 28,685) genes, respectively. Both analyses were performed with an F84 distance model, a window size of 1,500 base pairs and a step size of 300 base pairs. 


\section{RESEARCH LETTER}

Extended Data Table 1 | Summary of sampling detail and CoV prevalence

\begin{tabular}{lll} 
Sampling time & $\begin{array}{l}\text { Total number of swab or fecal samples } \\
\text { collected }\end{array}$ & Number of CoV PCR positive samples (\%) \\
\hline April, 2011 & 14 & $1(7.1)$ \\
October, 2011 & 10 & $3(30)$ \\
May, 2012 & 54 & $4(7.4)$ \\
September, 2012 & 39 & $19(48.7)$ \\
\hline
\end{tabular}


Extended Data Table 2 | Genomic sequence identities of bat SL-CoVs with SARS-CoVs

\begin{tabular}{|c|c|c|c|c|c|c|c|c|c|c|c|c|}
\hline \multirow[b]{3}{*}{ CoVs } & \multirow[b]{3}{*}{$\begin{array}{l}\text { Genome } \\
\text { size (nt) }\end{array}$} & \multicolumn{11}{|c|}{ Pairwise genomic nucleotide acids identity (\%) } \\
\hline & & \multicolumn{7}{|c|}{ Bat SARS-Like CoVs } & \multicolumn{4}{|c|}{$\begin{array}{l}\text { Human and civet } \\
\text { SARS-CoVs }\end{array}$} \\
\hline & & SHC014 & Rs672 & Rp3 & Rf1 & Rm1 & HKU3-1 & BM48-31 & GZO2 & BJ01 & Tor2 & SZ3 \\
\hline 3367 & 29,787 & 98.8 & 92.5 & 93.2 & 87.3 & 88.0 & 87.8 & 76.9 & 95.4 & 95.3 & 95.4 & 95.3 \\
\hline SHC014 & 29,787 & - & 92.6 & 93.2 & 87.3 & 88.1 & 87.8 & 77.0 & 95.2 & 95.1 & 95.1 & 95.1 \\
\hline Rs672 & 29,059 & & - & 92.4 & 86.2 & 87.4 & 87.0 & 75.2 & 90.9 & 90.9 & 90.8 & 91.0 \\
\hline Rp3 & 29,736 & & & - & 88.3 & 90.3 & 89.6 & 77.0 & 92.1 & 92.0 & 92.1 & 92.0 \\
\hline Rf1 & 29,709 & & & & - & 89.4 & 88.4 & 76.6 & 87.2 & 87.1 & 87.2 & 87.1 \\
\hline Rm1 & 29,749 & & & & & - & 90.1 & 76.4 & 87.6 & 87.5 & 87.5 & 87.5 \\
\hline HKU3-1 & 29,728 & & & & & & - & 76.8 & 87.4 & 87.3 & 87.4 & 87.3 \\
\hline BM48-31 & 29,276 & & & & & & & - & 76.9 & 77.1 & 77.0 & 76.9 \\
\hline GZ02 & 29,760 & & & & & & & & - & 99.6 & 99.6 & 99.7 \\
\hline BJ01 & 29,725 & & & & & & & & & - & 99.8 & 99.6 \\
\hline Tor2 & 29,751 & & & & & & & & & & - & 99.5 \\
\hline SZ3 & 29,741 & & & & & & & & & & & - \\
\hline
\end{tabular}




\section{RESEARCH LETTER}

Extended Data Table 3 | Genomic annotation and comparison of bat SL-CoV Rs3367 with human/civet SARS-CoVs and other bat SL-CoVs

\begin{tabular}{|c|c|c|c|c|c|c|c|c|c|c|c|c|c|c|}
\hline \multirow[b]{3}{*}{ ORFs } & \multirow[b]{3}{*}{ Start-End (nt.) } & \multirow[b]{3}{*}{$\begin{array}{c}\text { No. of } \\
\text { Nt. }\end{array}$} & \multirow[b]{3}{*}{$\begin{array}{c}\text { No. of } \\
\text { Aa. }\end{array}$} & \multirow[b]{3}{*}{ TRS } & \multicolumn{10}{|c|}{ ORF Identity nt/aa (\%) } \\
\hline & & & & & \multicolumn{4}{|c|}{ Human and civet SARS-CoVs } & \multicolumn{6}{|c|}{ Bat SARS-like CoVs } \\
\hline & & & & & $\begin{array}{c}\mathrm{GZO} \\
2\end{array}$ & BJ01 & Tor2 & sZ3 & Rs672 & Rp3 & Rf1 & $\mathrm{Rm} 1$ & HKU3-1 & BM48-31 \\
\hline P1a & $265-13,398$ & 13,134 & 4,377 & ACGAAC $_{192}$ AUG & $96.7 / 97.9$ & $96.6 / 97.9$ & $96.8 / 97.9$ & $96.8 / 98.1$ & $93.3 / 94.2$ & $95.5 / 96.9$ & $88.1 / 94.0$ & $87.9 / 93.3$ & $87.9 / 94.2$ & $76.3 / 80.8$ \\
\hline P1b & $13,398-21,485$ & 8,088 & 2,695 & & $96.3 / 99.2$ & $96.3 / 99.2$ & $96.3 / 99.2$ & $96.3 / 99.2$ & $97.2 / 99.2$ & $97.2 / 99.2$ & $90.6 / 98.4$ & $91.0 / 98.7$ & $90.7 / 98.5$ & $83.4 / 93.7$ \\
\hline s & $21,492-25,262$ & 3,771 & 1,256 & ACGAACAUG & $88.3 / 90.1$ & $88.2 / 90.0$ & $88.1 / 89.8$ & $88.2 / 90.0$ & $76.5 / 78.2$ & $76.0 / 79.1$ & $74.0 / 77.4$ & $76.3 / 79.1$ & $75.6 / 78.2$ & $70.2 / 74.5$ \\
\hline (S1) * & 21,493-23,535 & 2,043 & 681 & & $78.2 / 81.1$ & $78.2 / 80.9$ & $78.1 / 80.6$ & $78.2 / 81.1$ & $65.1 / 62.2$ & $63.9 / 63.0$ & $62.9 / 62.5$ & $64.7 / 63.3$ & $65.2 / 63.4$ & $62.2 / 64.7$ \\
\hline$(\mathrm{S} 2)^{*}$ & $23,536-25,263$ & 1,728 & 575 & & $98.1 / 99.3$ & $98.1 / 99.3$ & $98.1 / 99.3$ & $98.1 / 99.1$ & $87.9 / 94.8$ & $88.1 / 95.8$ & $85.1 / 92.7$ & $87.9 / 95.4$ & $86 / 93.5$ & $76.6 / 88.2$ \\
\hline ORF3a & $25,271-26,095$ & 825 & 274 & $\mathrm{ACGAAC}_{2} \mathrm{AUG}$ & $99.2 / 98.1$ & $98.6 / 97.0$ & $98.7 / 97.0$ & $98.5 / 96.7$ & $90.4 / 90.8$ & $84.1 / 84.3$ & $88.8 / 86.8$ & $83.6 / 84.3$ & $83.1 / 82.4$ & $72.1 / 71.2$ \\
\hline ORF3b & $25,692-26,036$ & 345 & 114 & & $99.1 / 99.1$ & $98.2 / 98.2$ & $98.2 / 98.2$ & $97.9 / 97.3$ & $99.1 / 98.2$ & $N / D$ & $82.6 / 92.1$ & $\mathrm{~N} / \mathrm{D}$ & $N / D$ & $N / D$ \\
\hline E & $26,120-26,350$ & 231 & 76 & $\operatorname{ACGAAC}_{2} A \cup G$ & $98.7 / 98.6$ & $98.7 / 98.6$ & $98.7 / 98.6$ & $98.7 / 98.6$ & $99.1 / 98.6$ & $97.8 / 98.6$ & $96.5 / 96.0$ & $96.1 / 97.3$ & $97.4 / 98.6$ & $91.3 / 93.4$ \\
\hline M & $26,401-27,066$ & 666 & 221 & $\mathrm{ACGAAC}_{44} \mathrm{AUG}$ & $97.4 / 98.1$ & $97.2 / 98.1$ & $97.2 / 98.1$ & $97.2 / 97.7$ & $98.7 / 99.5$ & $93.3 / 98.1$ & $96.3 / 98.6$ & $93.2 / 95.4$ & $93.9 / 96.8$ & $78.5 / 88.1$ \\
\hline ORF6 & $27,077-27,268$ & 192 & 63 & $\mathrm{ACGAAC}_{155}$ AUG & $97.3 / 95.2$ & $96.8 / 93.6$ & $97.3 / 95.2$ & $97.3 / 95.2$ & $97.3 / 96.8$ & $95.8 / 92.0$ & $94.2 / 92.0$ & $95.3 / 92$ & $94.7 / 90.4$ & $63.5 / 49.2$ \\
\hline ORF7a & $27,276-27,644$ & 369 & 122 & ACGAACAUG & $94.5 / 95.9$ & $94.5 / 95.9$ & $94.5 / 95.9$ & $94.5 / 95.9$ & $97.8 / 100$ & $96.2 / 99.1$ & $92.9 / 95.0$ & $93.4 / 97.5$ & $93.2 / 97.5$ & $62.3 / 58.1$ \\
\hline ORF7b & $27,641-27,776$ & 135 & 44 & & $96.2 / 93.1$ & $96.2 / 93.1$ & $96.2 / 93.1$ & $96.2 / 93.1$ & $99.2 / 100$ & $99.2 / 100$ & $97.7 / 97.7$ & $99.2 / 100$ & $93.3 / 95.4$ & $62.9 / 63.6$ \\
\hline ORF8 & $27,782-28,147$ & 366 & 121 & ACGAACAUG & $47.1 / 46.3$ & N/A & N/A & $47.1 / 46.3$ & $97.8 / 100$ & $85.2 / 90.2$ & $46.2 / 39.0$ & $85.7 / 90.2$ & $85.7 / 85.3$ & $\mathrm{~N} / \mathrm{A}$ \\
\hline $\mathrm{N}$ & $28,162-29,430$ & 1,269 & 422 & $\operatorname{ACGAAC}_{8} \mathrm{AUG}$ & $98.3 / 99.5$ & $98.4 / 99.5$ & $98.4 / 99.5$ & $98.4 / 99.5$ & $98 / 98.5$ & $96.6 / 97.6$ & $93.7 / 95.2$ & $96.2 / 97.1$ & $95.9 / 96.2$ & $77.9 / 87.2$ \\
\hline $\mathrm{s} 2 \mathrm{~m}$ & $29,628-29,668$ & 41 & & & 97.5 & 97.5 & 97.5 & 97.5 & 100 & 100 & 100 & 100 & 100 & 95.1 \\
\hline
\end{tabular}

* $\mathrm{S} 1$, the $\mathrm{N}$-terminal domain of the coronavirus $\mathrm{S}$ protein responsible for receptor binding. $\mathrm{S} 2$, the $\mathrm{S}$ protein $\mathrm{C}$-terminal domain responsible for membrane fusion.

The ORFs in the genome were predicted and potential protein sequences were translated. The pairwise comparisons were conducted for all ORFs at nucleotide acids (nt) and amino acids (aa) levels. The s $2 \mathrm{~m}$ were compared at $\mathrm{nt}$ level. TRS: Transcription regulating-sequences; N/D, not done; N/A, not available. 
Extended Data Table 4 | Genomic annotation and comparison of bat SL-CoV RsSHC014 with human/civet SARS-CoVs and other bat SL-CoVs

\begin{tabular}{|c|c|c|c|c|c|c|c|c|c|c|c|c|c|c|}
\hline \multirow[b]{3}{*}{ ORFs } & \multirow[b]{3}{*}{ Start-End (nt.) } & \multirow[b]{3}{*}{$\begin{array}{c}\text { No. of } \\
\text { Nt. }\end{array}$} & \multirow[b]{3}{*}{$\begin{array}{c}\text { No. of } \\
\text { Aa. }\end{array}$} & \multirow[b]{3}{*}{ TRS } & \multicolumn{10}{|c|}{ ORF Identity nt/aa (\%) } \\
\hline & & & & & \multicolumn{4}{|c|}{ Human and civet SARS-CoVs } & \multicolumn{6}{|c|}{ Bat SARS-like CoVs } \\
\hline & & & & & $\begin{array}{c}\text { GZO } \\
2\end{array}$ & BJ01 & Tor2 & sz3 & Rs672 & Rp3 & Rf1 & $\mathrm{Rm} 1$ & HKU3-1 & BM48-31 \\
\hline P1a & $265-13,398$ & 13,134 & 4,377 & ACGAAC $_{192}$ AUG & $96.7 / 97.9$ & $96.6 / 97.9$ & $96.8 / 97.9$ & $96.8 / 98.1$ & $93.3 / 94.2$ & $95.5 / 96.9$ & $88.1 / 94.0$ & $87.9 / 93.3$ & $87.9 / 94.2$ & $76.3 / 80.8$ \\
\hline P1b & $13,398-21,485$ & 8,088 & 2,695 & & $96.3 / 99.2$ & $96.3 / 99.2$ & $96.3 / 99.2$ & $96.3 / 99.2$ & $97.2 / 99.2$ & $97.2 / 99.2$ & $90.6 / 98.4$ & $91.0 / 98.7$ & $90.7 / 98.5$ & $83.4 / 93.7$ \\
\hline $\mathbf{s}$ & $21,492-25,262$ & 3,771 & 1,256 & ACGAACAUG & $88.3 / 90.1$ & $88.2 / 90.0$ & $88.1 / 89.8$ & $88.2 / 90.0$ & $76.5 / 78.2$ & $76.0 / 79.1$ & $74.0 / 77.4$ & $76.3 / 79.1$ & $75.6 / 78.2$ & $70.2 / 74.5$ \\
\hline (s1) * & $21,493-23,535$ & 2,043 & 681 & & $78.2 / 81.1$ & $78.2 / 80.9$ & $78.1 / 80.6$ & $78.2 / 81.1$ & $65.1 / 62.2$ & $63.9 / 63.0$ & $62.9 / 62.5$ & $64.7 / 63.3$ & $65.2 / 63.4$ & $62.2 / 64.7$ \\
\hline$(\mathbf{s} 2)^{*}$ & $23,536-25,263$ & 1,728 & 575 & & $98.1 / 99.3$ & $98.1 / 99.3$ & $98.1 / 99.3$ & $98.1 / 99.1$ & $87.9 / 94.8$ & $88.1 / 95.8$ & $85.1 / 92.7$ & $87.9 / 95.4$ & $86 / 93.5$ & $76.6 / 88.2$ \\
\hline ORF3a & $25,271-26,095$ & 825 & 274 & $\mathrm{ACGAAC}_{2} \mathrm{AUG}$ & $99.2 / 98.1$ & $98.6 / 97.0$ & $98.7 / 97.0$ & $98.5 / 96.7$ & $90.4 / 90.8$ & $84.1 / 84.3$ & $88.8 / 86.8$ & $83.6 / 84.3$ & $83.1 / 82.4$ & $72.1 / 71.2$ \\
\hline ORF3b & $25,692-26,036$ & 345 & 114 & & $99.1 / 99.1$ & $98.2 / 98.2$ & $98.2 / 98.2$ & 97.9/97.3 & 99.1/98.2 & $\mathrm{N} / \mathrm{D}$ & $82.6 / 92.1$ & N/D & N/D & N/D \\
\hline $\mathbf{E}$ & $26,120-26,350$ & 231 & 76 & $\operatorname{ACGAAC}_{2} \mathrm{AUG}$ & $98.7 / 98.6$ & $98.7 / 98.6$ & $98.7 / 98.6$ & $98.7 / 98.6$ & $99.1 / 98.6$ & $97.8 / 98.6$ & $96.5 / 96.0$ & $96.1 / 97.3$ & $97.4 / 98.6$ & $91.3 / 93.4$ \\
\hline$M$ & $26,401-27,066$ & 666 & 221 & $\mathrm{ACGAAC}_{44}$ AUG & $97.4 / 98.1$ & $97.2 / 98.1$ & $97.2 / 98.1$ & $97.2 / 97.7$ & $98.7 / 99.5$ & $93.3 / 98.1$ & $96.3 / 98.6$ & $93.2 / 95.4$ & $93.9 / 96.8$ & $78.5 / 88.1$ \\
\hline ORF6 & $27,077-27,268$ & 192 & 63 & ACGAAC $_{155}$ AUG & $97.3 / 95.2$ & $96.8 / 93.6$ & $97.3 / 95.2$ & $97.3 / 95.2$ & $97.3 / 96.8$ & $95.8 / 92.0$ & $94.2 / 92.0$ & $95.3 / 92$ & $94.7 / 90.4$ & $63.5 / 49.2$ \\
\hline ORF7a & $27,276-27,644$ & 369 & 122 & ACGAACAUG & $94.5 / 95.9$ & $94.5 / 95.9$ & $94.5 / 95.9$ & $94.5 / 95.9$ & $97.8 / 100$ & $96.2 / 99.1$ & $92.9 / 95.0$ & $93.4 / 97.5$ & $93.2 / 97.5$ & $62.3 / 58.1$ \\
\hline ORF7b & $27,641-27,776$ & 135 & 44 & & $96.2 / 93.1$ & $96.2 / 93.1$ & $96.2 / 93.1$ & $96.2 / 93.1$ & $99.2 / 100$ & $99.2 / 100$ & $97.7 / 97.7$ & $99.2 / 100$ & $93.3 / 95.4$ & $62.9 / 63.6$ \\
\hline ORF8 & $27,782-28,147$ & 366 & 121 & ACGAACAUG & $47.1 / 46.3$ & N/A & N/A & $47.1 / 46.3$ & $97.8 / 100$ & $85.2 / 90.2$ & $46.2 / 39.0$ & $85.7 / 90.2$ & $85.7 / 85.3$ & N/A \\
\hline $\mathrm{N}$ & $28,162-29,430$ & 1,269 & 422 & $\operatorname{ACGAAC}_{8} \mathrm{AUG}$ & $98.3 / 99.5$ & $98.4 / 99.5$ & $98.4 / 99.5$ & $98.4 / 99.5$ & $98 / 98.5$ & $96.6 / 97.6$ & $93.7 / 95.2$ & $96.2 / 97.1$ & $95.9 / 96.2$ & $77.9 / 87.2$ \\
\hline $\mathrm{s} 2 \mathrm{~m}$ & $29,628-29,668$ & 41 & & & 97.5 & 97.5 & 97.5 & 97.5 & 100 & 100 & 100 & 100 & 100 & 95.1 \\
\hline
\end{tabular}

* 1 , the $\mathrm{N}$-terminal domain of the coronavirus $\mathrm{S}$ protein responsible for receptor binding. $\mathrm{S} 2$, the $\mathrm{S}$ protein $\mathrm{C}$-terminal domain responsible for membrane fusion.

The ORFs in the genome were predicted and potential protein sequences were translated. The pairwise comparisons were conducted for all ORFs at nucleotide acids (nt) and amino acids (aa) levels. The s2 $\mathrm{m}$ were compared at $\mathrm{nt}$ level. TRS: Transcription regulating-sequences; N/D, not done; N/A, not available. 


\section{RESEARCH LETTER}

Extended Data Table 5 | Cell lines used for virus isolation and susceptibility tests

\begin{tabular}{|c|c|c|c|}
\hline Cell lines & Species (organ) origin & Medium & Infectivity \\
\hline 293T & Human (kidney) & \multirow{6}{*}{ DMEM+10\%FBS } & - \\
\hline Hela & Human (cervix) & & - \\
\hline VeroE6 & Monkey (kidney) & & + \\
\hline PK15 & Pig (kidney) & & + \\
\hline BHK21 & Hamster (kidney) & & - \\
\hline A549 & Human (alveolar basal epithelial) & & + \\
\hline BK & Myotis davidii (kidney) & RPMI $1640+10 \%$ FBS & - \\
\hline RSKT & Rhinolophus sinicus (kidney) & \multirow{4}{*}{ DMEM/F12+10\%FBS } & + \\
\hline MCKT & Myotis chinensis (kidney) & & - \\
\hline PaKi & Pteropus alecto (kidney) & & - \\
\hline RLK & Rousettus leschenaulti (kidney) & & - \\
\hline
\end{tabular}

* Infectivity was determined by the presence of viral antigen detected by immunofluorescence assay. 